\title{
Real exchange rate variability in a two-country business cycle model ${ }^{*}$
}

\author{
Håkon Tretvoll, ${ }^{\dagger}$
}

November 20, 2012

\begin{abstract}
Real exchange rate fluctuations have important implications for our understanding of the sources and transmission of international business cycles, and the degree of international risk sharing. In most two-country business cycle models, the real exchange rate is determined by differences in consumption and leisure across countries, and its standard deviation is significantly smaller than we see in the data. With recursive preferences the marginal utility of consumption today also depends on innovations in agents' future utilities. Real exchange rate movements are therefore partially disconnected from current quantities. With permanent cointegrated technology shocks and home bias, the model generates realistic variability in the real exchange rate. The mechanism is similar to related work on asset pricing, and the model produces highly volatile stochastic discount factors with more realistic asset pricing implications. In addition, there is modest improvement in the cross-country correlations of quantities, as investment and employment are positively correlated across countries.
\end{abstract}

JEL Classification Codes: E32; F31; F32; F44

Keywords: International business cycles, recursive preferences, real exchange rate dynamics, home bias.

\footnotetext{
*I would like to thank David Backus, Mark Dean, Fernando Leibovici, Tom Sargent, Matt Smith, Christopher Tonetti and Stan Zin for helpful comments and useful discussions. I would also like to thank participants at the Macroeconomics Lunch Seminar and the International Reading group at NYU Stern for useful feedback. All remaining errors are my own. I welcome comments, including references to related papers I inadvertently overlooked.

${ }^{\dagger}$ New York University; hakon@nyu.edu.
} 


\section{Introduction}

A central puzzle in international macroeconomics and finance is the high volatility of the real exchange rate. A large literature has therefore developed concerning the cause of exchange rate fluctuations in international business cycle models. ${ }^{1}$ While this literature aims to capture the joint dynamics of quantities and relative prices, it tends to ignore the implications for pricing financial assets. The mechanism proposed in this paper to generate both high real exchange rate volatility and volatile stochastic discount factors with realistic asset pricing implications, is to model agents with recursive preferences of the form discussed by Epstein and Zin (1989) in the international business cycle framework.

The real exchange rate is the relative price of consumption across countries. In the standard model, where agents have power utility over a composite of consumption and leisure, only the short-run differences in these quantities across countries affect the current currency value. The low volatility of these differences therefore implies a low standard deviation of the real exchange rate. With recursive preferences, the exchange rate adjusts to reflect both current and future differences in the allocations. Recursive preferences allow agents' attitudes towards risk and substitution over time to be modeled separately. This makes preferences non-separable over future states and implies that agents want to smooth future utility as well as consumption and leisure. They are therefore sensitive to the long-run prospects of the economy, and news about future consumption growth affects their marginal utility of consumption today. If the news implies future differences in consumption growth across countries, the effect on marginal utilities differ and this is reflected in the real exchange rate.

In the model, fluctuations in productivity growth generate dynamics in quantities and prices. With a unit root in the productivity process these shocks have permanent effects. For the two-country model to be consistent with balanced growth, productivities are also assumed to be cointegrated. This implies that the difference in productivity across countries is stationary, but persistent. The two countries specialize in the production of intermediate goods. These goods are traded internationally, and used as inputs in the production of final goods that are allocated to consumption and investment. There is home bias in final goods production, so in each country the domestic intermediate good is the main input. Persistent differences in levels of productivity lead to persistent fluctuations in the relative price of intermediate goods. Home bias implies that these relative price fluctuations affect the cost of consumption differently across countries, and therefore results in variability in the real exchange rate.

Together the three key components of the model deliver a highly variable real exchange rate: A cointegrated productivity process delivers persistent differences in technology levels and hence, in the relative price of inputs to final goods production. Home bias implies

\footnotetext{
${ }^{1}$ For example, Chari, Kehoe, and McGrattan (2002) consider monetary shocks and sticky prices. Raffo (2009) introduces investment specific technology shocks. Corsetti et al. (2008) and Rabanal et al. (2011) study economies with incomplete markets. These are discussed in more detail in section 1.1.
} 
that these relative price differences are reflected in the relative cost of consumption. Thus productivity shocks provide news about persistent differences in consumption growth across countries and when agents have recursive preferences the corresponding response in the real exchange rate is amplified.

Since Tallarini (2000) it is well known that the alternative preference specification applied in this paper enables a closed production economy to jointly match key moments of both quantities and asset prices. We show that this feature also applies in the international setting. The model is thus able to jointly match the volatility of the real exchange rate relative to output and produce highly volatile stochastic discount factors with more realistic asset pricing implications. The high volatility arises from agents' sensitivity to news about future consumption growth. This shows up as additional components of agents' stochastic discount factors, and with permanent productivity shocks, volatility is high due to these "long-run" components.

The model also produces realistic levels of goods trade and moderate improvements in the international comovements of investment and employment. In the equilibrium of the model, the amount of trade is determined by the elasticity of substitution between intermediate goods and the degree of home bias. In the baseline parameterization the elasticity of substitution is low as is common in the international macroeconomics literature, and the corresponding home bias is high. Complementarity between intermediate goods implies that employment is positively correlated across countries. This holds for both additive and recursive preferences, but the optimal risk sharing scheme when agents have recursive preferences also implies a positive cross-country correlation of investment. In that model, the larger relative price movements following productivity shocks and the corresponding increases in the wage and rental rate of capital, induce households to increase both labor supply and investment.

As the model features complete financial markets, a social planner's problem can be solved for the optimal allocations, and then the prices in the decentralized equilibrium can be obtained. However, when agents have recursive preferences, solving for the equilibrium with trade is not straightforward. To obtain a recursive formulation of the planner's problem, an additional state variable is required. One interpretation of the additional state is that the Pareto weights on the two countries evolve over time. With this interpretation, the dynamics of the Pareto weights are driven by the heterogeneous responses of households' utilities to productivity shocks, that arise from home bias. Higher productivity for one of the intermediate goods makes it easier for the planner to provide utility to the households who consume the final good produced with a bias towards the more abundant intermediate input. Therefore the planner will not equalize agents' continuation utilities. Instead the planner partly smooths utilities by increasing the share of intermediate goods allocated to the country hit with a relatively lower productivity shock. The increase in the share of available goods corresponds with an increase in the Pareto weight on that country. In the optimal risk sharing scheme chosen by the planner, the variation in the Pareto weights reflect the different effects of productivity shocks on agents marginal utilities of consump- 
tion. There is therefore a tight link between the Pareto weight dynamics and the amplified response in the real exchange rate in the decentralized equilibrium.

\section{$1.1 \quad$ Related literature}

There are large literatures on both international business cycles and real exchange rate fluctuations. One closely related paper is Rabanal, Rubio-Ramirez, and Tuesta (2011) who also study real exchange rate variability in an international business cycle model. As we do here, they build on the framework introduced by Backus et al. $(1992,1994)$ and further extended by Heathcote and Perri (2002). Rabanal et al. find that a model where trade in financial assets is restricted to a non-contingent bond can generate a high volatility of the real exchange rate relative to output when productivity shocks are cointegrated. Corsetti et al. (2008) find that an incomplete markets model with non-traded goods and a distribution sector can also generate high exchange rate variability with trend-stationary shocks. In this paper the focus is on a different mechanism that arises due to the alternative specification of preferences. The model presented here therefore has more realistic asset pricing implications, a dimension ignored by both Rabanal et al. and Corsetti et al. Our results complement theirs and show that high real exchange rate volatility is not necessarily due to incomplete financial markets.

Other papers have introduced different shocks to generate volatile real exchange rates. Chari et al. (2002) generate real exchange rate fluctuations from monetary shocks interacting with sticky prices. They obtain highly volatile real exchange rates, but Rabanal et al. argue that they require the variance of the monetary shocks to be counterfactually high in order to do so. Raffo (2009) and Mandelman et al. (2011) instead consider models with investment specific technology shocks in addition to shocks to productivity. The former argues that an appropriately calibrated process for investment specific shocks enables the model to explain several puzzles in international business cycles, including highly variable real exchange rates. The latter however, argues that when a carefully estimated process for the shocks to investment is fed into the model, its explanatory power is greatly diminished.

Colacito and Croce (2011a) study the implications for international asset pricing of introducing recursive preferences in a two-country endowment economy. They follow Bansal and Yaron (2004) and introduce consumption processes featuring small, but persistent long-run components. In their model there is perfect home bias and no trade in goods, and their results require that the long-run components are perfectly correlated across countries. They argue that growth and diffusion of technology can justify their assumptions, and in this paper a cointegrated productivity process endogenously implies long-run dynamics similar to those that they impose. In that respect our paper features a similar mechanism to Kaltenbrunner and Lochstoer (2010) who show how long-run risk arises endogenously in a production economy where agents have Epstein-Zin preferences.

A related paper with a different focus is Benigno and Nisticò (2012). They argue that a model with recursive preferences can explain the well documented portfolio bias towards 
domestic equities. The bias arises as domestic equities are a good hedge for real exchange rate risk which dominates the portfolio allocation when risk aversion is large. With recursive preferences increased risk aversion does not imply a low intertemporal elasticity of substitution and the portfolio home bias can therefore arise without implying the risk-free rate puzzle of Weil (1990). Benigno and Nisticò (2012) do not solve the complete general equilibrium model however, and therefore do not present the model's implications for the variability and comovements of quantities as we do here. Instead they focus only on the equations of the model that are necessary to characterize the optimal portfolio decision. In addition, the risks in their model are driven by exogenous processes for labor supply and markups rather than by endogenous responses to productivity shocks.

This paper is also related to the literature on recursive preferences with multiple agents. Jr. and Stokey (1984), Kan (1995) and Anderson (2005) discuss the formulation and solution of a recursive planner's problem in such environments. Anderson focuses on the dynamics of Pareto weights in a one good economy with heterogeneity in preference parameters. He finds that this leads to a degenerate stationary distribution. Colacito and Croce (2011c) on the other hand focus on Pareto weight dynamics in an endowment economy with two goods where agents derive utility from an aggregate consumption good with the two intermediate goods as inputs. They prove that there is a non-degenerate stationary distribution when heterogeneity between agents arises from home bias in the aggregation. Colacito and Croce (2011b) applies this framework in an asset pricing model featuring rare disasters. The economy presented here features a similar setup to Colacito and Croce, but we consider a business cycle model with production and endogenous labor supply. In addition, we do not restrict the intertemporal and intratemporal elasticities of substitution to be unity. A low elasticity of substitution between intermediate goods enables the model to jointly generate realistic levels of goods trade and volatile real exchange rates.

\subsection{Organization}

This paper is organized as follows. Section 2 describes an international business cycle model where agents have recursive preferences and derives the equilibrium conditions for that economy. Section 3 discusses a recursive formulation of the social planner's problem which allows us to solve for equilibrium allocations. In section 4 we parameterize the model using standard values from the international macroeconomics literature and discuss our main results. Section 5 considers some alternative parameterizations to highlight the main forces that drive the increased relative volatility of the real exchange rate in the model with recursive preferences. Section 6 concludes.

\section{The model}

The model presented here is similar to the international real business cycle models studied recently in Rabanal, Rubio-Ramirez, and Tuesta (2011) and earlier in Heathcote and 
Perri (2002) and Backus, Kehoe, and Kydland (1992, 1994). Our innovation is to model households with recursive preferences in this framework.

There are two countries referred to as "home" $h$, and "foreign" $f$. In each country an intermediate good is produced which is traded internationally, and a final good is produced using the two intermediate goods as inputs. For convenience we will occasionally refer to the final good produced in country $i \in\{h, f\}$ as "final good $i$ ", and the intermediate good produced in country $i$ as "intermediate good $i$ ". International financial asset markets are complete.

\subsection{Uncertainty}

Time is discrete. Each period there is a realization of a random event $z_{t}$, which denotes shocks to productivity in the two countries. In general allocations in period $t$ are functions of the history of these shocks up to and including time $t$, and of initial values for capital stocks $K_{i, 0}$ and asset holdings $A_{i, 0}$ for $i \in\{h, f\}$. For convenience we let $z^{t}=\left(K_{h, 0}, K_{f, 0}, A_{h, 0}, A_{f, 0}, z_{0}, z_{1}, \ldots, z_{t}\right)$ denote the vector of initial values and the history of events up to and including time $t$.

\subsection{Households}

In each country the representative, infinitely lived, agent maximizes a recursive utility function over an aggregate of the final consumption good and leisure. We will refer to the representative consumer in country $i$ as "agent $i$ ". As in Epstein and Zin (1989) and Weil (1990), preferences are modeled using the formulation from Kreps and Porteus (1978). The utility of agent $i \in\{h, f\}$ is defined by ${ }^{2}$

$$
U_{i, t}=\left[(1-\beta)\left(C_{i, t}^{\tau}\left(1-n_{i, t}\right)^{1-\tau}\right)^{\rho}+\beta\left(\mathbb{E}_{t}\left(U_{i, t+1}^{\alpha}\right)\right)^{\rho / \alpha}\right]^{1 / \rho}
$$

Here $\tau$ is the share of consumption in the consumption-leisure bundle, $\beta$ is the discount factor, the intertemporal elasticity of substitution (IES) over the consumption-leisure aggregate is $1 /(1-\rho)$, and risk aversion towards static gambles over the aggregate is measured by $1-\alpha$. When households have a preference for leisure the measure of risk aversion over consumption depends on both the household's consumption and labor margins, and is given by $\tau(1-\alpha)$. See Swanson (2009) for a detailed discussion of measures of risk aversion with leisure in the utility function.

\footnotetext{
${ }^{2}$ The special cases where $\rho=0$ or $\alpha=0$ are easily handled by taking the appropriate limits. For brevity these limiting expressions are not presented here.
} 
The household maximizes (1) subject to a budget constraint, a capital evolution equation, and given initial values of the capital stock $K_{i, 0}$ and asset holdings $A_{i, 0}$. The budget constraint in country $h$ is given by

$$
\begin{gathered}
C_{h, t}\left(z^{t}\right)+I_{h, t}\left(z^{t}\right)+\int_{z_{t+1} \mid z_{t}} q_{t}\left(z \mid z^{t}\right) A_{h, t}\left(z \mid z^{t}\right) d z= \\
W_{h, t}\left(z^{t}\right) n_{h, t}\left(z^{t}\right)+r_{h, t}\left(z^{t}\right) K_{h, t}\left(z^{t-1}\right)+A_{h, t}\left(z^{t}\right)
\end{gathered}
$$

Here $C_{h, t}\left(z^{t}\right) \geq 0$ is units of consumption of the final good in country $h, I_{h, t}\left(z^{t}\right) \geq 0$ is investment, $n_{h, t}\left(z^{t}\right) \in[0,1]$ is the fraction of time spent working, and $K_{h, t}\left(z^{t-1}\right) \geq 0$ is the capital stock in country $h$ at the beginning of period $t$. $W_{h, t}\left(z^{t}\right)$ is the wage in country $h$, and $r_{h, t}\left(z^{t}\right)$ is the rental rate of capital. The prices of both factor inputs are measured in units of the final good in country $h$. The household has access to a complete set of state contingent securities that deliver one unit of the final good from country $h . A_{h, t}\left(z^{t}\right)$ is the number of such claims owned by the representative agent in country $h$, and $q_{t}\left(z_{t+1} \mid z^{t}\right)$ is the price of one such claim in time $t+1$ after history $z^{t}$ measured in units of final good $h$. Households issue state contingent securities subject to state-by-state debt limits that ensure that it is always feasible for the household to repay its state contingent debt. ${ }^{3}$

The budget constraint in country $f$ is similar, but is written in terms of the final good in that country. So the prices of the factor inputs $W_{f, t}\left(z^{t}\right)$ and $r_{f, t}\left(z^{t}\right)$ are measured in terms of the final good in $f$. The budget constraint is thus

$$
\begin{aligned}
& C_{f, t}\left(z^{t}\right)+I_{f, t}\left(z^{t}\right)+\frac{1}{e_{t}\left(z^{t}\right)} \int_{z_{t+1} \mid z_{t}} q_{t}\left(z \mid z^{t}\right) A_{f, t}\left(z \mid z^{t}\right) d z= \\
& W_{f, t}\left(z^{t}\right) n_{f, t}\left(z^{t}\right)+r_{f, t}\left(z^{t}\right) K_{f, t}\left(z^{t-1}\right)+\frac{A_{f, t}\left(z^{t}\right)}{e_{t}\left(z^{t}\right)}
\end{aligned}
$$

where $e_{t}\left(z_{t}\right)$ is the real exchange rate defined as the relative price of the final good in country $f$ relative to the final good in country $h$.

Finally, the capital evolution equation in country $i \in\{h, f\}$ is

$$
K_{i, t+1}\left(z^{t}\right)=(1-\delta) K_{i, t}\left(z^{t-1}\right)+I_{i, t}\left(z^{t}\right)
$$

where $\delta$ is the rate of depreciation which is the same across countries.

\section{$2.3 \quad$ Firms}

In each country there are producers of intermediate and final goods. In this section we describe these firms' problems and the process for productivity in the two countries.

\footnotetext{
${ }^{3}$ These limits are often referred to as "natural" debt limits, and in the equilibrium of this model, they are never binding.
} 


\subsubsection{Final goods production}

A representative firm in the final goods sector produces using a CES production function where the inputs are the intermediate goods produced in both countries. In each country there is a bias in the final goods production towards the intermediate good produced in that country. The demand for intermediate good $i$ in country $j$ is denoted by $X_{i j, t}$ for $i, j \in\{h, f\}$. The production functions of the final goods in the two countries are given by

$$
\begin{aligned}
& G_{h}\left(X_{h h, t}\left(z^{t}\right), X_{h f, t}\left(z^{t}\right)\right)=\left[\eta\left(X_{h h, t}\left(z^{t}\right)\right)^{\frac{\sigma-1}{\sigma}}+(1-\eta)\left(X_{h f, t}\left(z^{t}\right)\right)^{\frac{\sigma-1}{\sigma}}\right]^{\frac{\sigma}{\sigma-1}} \\
& G_{f}\left(X_{f h, t}\left(z^{t}\right), X_{f f, t}\left(z^{t}\right)\right)=\left[(1-\eta)\left(X_{f h, t}\left(z^{t}\right)\right)^{\frac{\sigma-1}{\sigma}}+\eta\left(X_{f f, t}\left(z^{t}\right)\right)^{\frac{\sigma-1}{\sigma}}\right]^{\frac{\sigma}{\sigma-1}}
\end{aligned}
$$

The parameter $\sigma$ is the elasticity of substitution between the two intermediate goods ${ }^{4}$, and home bias in final goods production is given by each country putting weight $\eta>1 / 2$ on the intermediate good produced in that country.

The representative final goods producers take the prices of the intermediate inputs as given and solve the following problem:

$$
\max _{X_{i h, t}\left(z^{t}\right), X_{i f, t}\left(z^{t}\right) \geq 0} G_{i}\left(X_{i h, t}\left(z^{t}\right), X_{i f, t}\left(z^{t}\right)\right)-q_{i h, t}\left(z^{t}\right) X_{i h, t}\left(z^{t}\right)-q_{i f, t}\left(z^{t}\right) X_{i f, t}\left(z^{t}\right)
$$

where $q_{i j, t}\left(z^{t}\right)$ is the price in country $i$ of intermediate good $j$ in units of final good $i$.

\subsubsection{Intermediate goods production}

In each country, a representative firm in the intermediate goods sector produces using capital and labor with a standard constant returns to scale production function. These firms take prices of goods and factor inputs as given and maximize profits by solving

$\max _{n_{i, t}\left(z^{t}\right), K_{i, t}\left(z^{t-1}\right) \geq 0} q_{i i, t}\left(z^{t}\right) K_{i, t}\left(z^{t-1}\right)^{\theta}\left(Z_{i, t}\left(z^{t}\right) n_{i, t}\left(z^{t}\right)\right)^{1-\theta}-W_{i, t}\left(z^{t}\right) n_{i, t}\left(z^{t}\right)-r_{i, t}\left(z^{t}\right) K_{i, t}\left(z^{t-1}\right)$

where $Z_{i, t}\left(z^{t}\right)$ is the labor-augmenting productivity in country $i$, and $\theta$ is the share of capital in production which is the same across countries. Gross domestic product in country $i$ in units of final good $i$ is denoted $Y_{i, t}\left(z^{t}\right)$ and is given by

$$
Y_{i, t}\left(z^{t}\right)=q_{i i, t}\left(z^{t}\right) K_{i, t}\left(z^{t-1}\right)^{\theta}\left(Z_{i, t}\left(z^{t}\right) n_{i, t}\left(z^{t}\right)\right)^{1-\theta}
$$

\footnotetext{
${ }^{4}$ For $\sigma=1$ the final goods production function is Cobb-Douglas.
} 


\subsubsection{Productivity}

Following Rabanal et al. (2011) we let $\log Z_{h, t}$ and $\log Z_{f, t}$ be cointegrated of order $C(1,1)$. The law of motion for the log-first differences of productivity in the home and the foreign country is specified by the following VECM:

$$
\left(\begin{array}{c}
\Delta \log Z_{h, t} \\
\Delta \log Z_{f, t}
\end{array}\right)=\left(\begin{array}{c}
\phi_{0 h} \\
\phi_{0 f}
\end{array}\right)+\left[\log Z_{h, t-1}-\kappa \log Z_{f, t-1}\right]\left(\begin{array}{c}
\phi_{1 h} \\
\phi_{1 f}
\end{array}\right)+\left(\begin{array}{c}
\varepsilon_{h, t} \\
\varepsilon_{f, t}
\end{array}\right)
$$

where $(1,-\kappa)$ is the cointegrating vector, $\left(\varepsilon_{h, t}, \varepsilon_{f, t}\right)^{T} \sim N(0, \Sigma)$, and $\Delta$ is the first-difference operator.

\subsection{International trade and prices}

International trade in the intermediate inputs is costless, and the law of one price holds. As the prices in the respective countries are denoted in terms of the local final goods, the following equation holds for the price of intermediate good $i \in\{h, f\}$ :

$$
q_{h i, t}\left(z^{t}\right)=e_{t}\left(z^{t}\right) q_{f i, t}\left(z^{t}\right)
$$

Therefore the real exchange rate can be expressed in terms of the prices of either of the intermediate goods in the two countries.

$$
e_{t}\left(z^{t}\right)=\frac{q_{h i, t}\left(z^{t}\right)}{q_{f i, t}\left(z^{t}\right)}, \quad i=h, f
$$

In addition, the terms of trade is defined as the price of imports in country $h$ relative to exports from country $h$ (i.e. the price of intermediate good $f$ relative to intermediate $\operatorname{good} h)$ :

$$
p_{t}\left(z^{t}\right)=\frac{q_{h f, t}\left(z^{t}\right)}{q_{h h, t}\left(z^{t}\right)}
$$

Other variables of interest related to international trade are the import ratio and net exports. For country $i$ we denote the import ratio $i r_{i, t}\left(z^{t}\right)$ and, following Heathcote and Perri (2002), define it as the ratio of imports to non-traded domestic intermediate good production:

$$
i r_{i, t}\left(z^{t}\right)=\frac{X_{i j, t}\left(z^{t}\right)}{X_{i i, t}\left(z^{t}\right)} \quad j \neq i
$$

Net exports as a fraction of GDP in country $i$ is denoted $n x_{i, t}\left(z^{t}\right)$ and is given by

$$
n x_{i, t}\left(z^{t}\right)=\frac{q_{i i, t}\left(z^{t}\right) X_{j i, t}\left(z^{t}\right)-q_{i j, t}\left(z^{t}\right) X_{i j, t}\left(z^{t}\right)}{Y_{i, t}\left(z^{t}\right)} \quad j \neq i
$$




\subsection{Market clearing}

The model is closed with market clearing conditions in the markets for the final and intermediate goods in each country, as well as in the international financial asset market. The state-contingent claims are in zero net supply, so after every history $s^{t}$ we have for every possible state $s_{t+1}$ in the subsequent period that

$$
A_{h, t}\left(z_{t+1} \mid z^{t}\right)+A_{f, t}\left(z_{t+1} \mid z^{t}\right)=0
$$

In the markets for the final and intermediate goods the market clearing conditions are given by

$$
\begin{aligned}
G_{i}\left(X_{i h, t}\left(z^{t}\right), X_{i f, t}\left(z^{t}\right)\right) & =C_{i, t}\left(z^{t}\right)+I_{i, t}\left(z^{t}\right) & & i \in\{h, f\} \\
K_{i, t}\left(z^{t-1}\right)^{\theta}\left(Z_{i, t}\left(z^{t}\right) n_{i, t}\left(z^{t}\right)\right)^{1-\theta} & =X_{h i, t}\left(z^{t}\right)+X_{f i, t}\left(z^{t}\right) & & i \in\{h, f\}
\end{aligned}
$$

\subsection{Definition of equilibrium}

Given the law of motion for productivity defined by equation (9), an equilibrium in this economy is a set of allocations for households in both countries, $C_{i, t}\left(z^{t}\right), n_{i, t}\left(z^{t}\right), I_{i, t}\left(z^{t}\right)$, $K_{i, t}\left(z^{t}\right)$, and $A_{i, t}\left(z^{t}\right)$ for $i \in\{h, f\}$; allocations for intermediate good producers in both countries $X_{i j, t}\left(z^{t}\right)$ for $i, j \in\{h, f\}$; allocations for final good producers in both countries $G_{i}\left(X_{i h, t}\left(z^{t}\right), X_{i f, t}\left(z^{t}\right)\right)$ for $i \in\{h, f\}$; intermediate goods prices in both countries $q_{i j, t}\left(z^{t}\right)$ for $i, j \in\{h, f\}$; factor prices in both countries $W_{i, t}\left(z^{t}\right)$ and $r_{i, t}\left(z^{t}\right)$, and the prices of statecontingent assets $q_{t}\left(z_{t+1} \mid z^{t}\right)$ such that: $(i)$ given prices, the households' allocations solve the households' problem; (ii) given prices, the intermediate goods producers' allocations solve the intermediate goods producers' problem; (iii) given prices, the final goods producers' allocations solve the final goods producers' problem; (iv) markets clear.

\subsection{Equilibrium conditions}

The equilibrium conditions include the first-order conditions of the households, and the intermediate and final goods producing firms in both countries. In addition, there are the laws of motion for productivity and capital, the production functions, and the market clearing conditions. 


\subsubsection{Households}

The households' first-order conditions for consumption and labor supply are

$$
\begin{gathered}
(1-\beta) \tau U_{i, t}\left(z^{t}\right)^{1-\rho} C_{i, t}\left(z^{t}\right)^{\tau \rho-1}\left(1-n_{i, t}\left(z^{t}\right)\right)^{(1-\tau) \rho}=\lambda_{i, t}\left(z^{t}\right) \\
\frac{1-\tau}{\tau} \frac{C_{i, t}\left(z^{t}\right)}{1-n_{i, t}\left(z^{t}\right)}=W_{i, t}\left(z^{t}\right)
\end{gathered}
$$

where $\lambda_{i, t}\left(z^{t}\right)$ is the lagrange multiplier on the household's budget constraint. With the preferences specified in equation (1), the households' stochastic discount factors $m_{i, t+1}\left(z_{t+1} \mid z^{t}\right)$ are given by

$$
\begin{aligned}
& m_{i, t+1}\left(z_{t+1} \mid z^{t}\right)= \\
& \quad \beta\left(\frac{C_{i, t+1}\left(z_{t+1} \mid z^{t}\right)}{C_{i, t}\left(z^{t}\right)}\right)^{\tau \rho-1}\left(\frac{1-n_{i, t+1}\left(z_{t+1} \mid z^{t}\right)}{1-n_{i, t}\left(z^{t}\right)}\right)^{(1-\tau) \rho}\left(\frac{U_{i, t+1}\left(z_{t+1} \mid z^{t}\right)}{\zeta_{t}\left(U_{i, t+1}\right)}\right)^{\alpha-\rho}
\end{aligned}
$$

where $\zeta_{t}\left(U_{i, t+1}\right)=\left(\mathbb{E}_{t} U_{i, t+1}^{\alpha}\right)^{1 / \alpha}$ is the certainty equivalent of future utility, and $\mathbb{E}_{t}$ is the conditional expectation operator conditioning on information available at time $t$.

The first-order condition with respect to capital delivers the standard equation for pricing returns

$$
1=\mathbb{E}_{t}\left(m_{i, t+1}\left(r_{i, t+1}+1-\delta\right) \mid z^{t}\right)
$$

The remaining first-order condition for the households with respect to the choice of statecontingent assets, deliver the following expressions for the asset prices:

$$
\begin{aligned}
q_{t}\left(z_{t+1} \mid z^{t}\right) & =\pi\left(z_{t+1} \mid z^{t}\right) m_{h, t+1}\left(z_{t+1} \mid z^{t}\right) \\
& =\pi\left(z_{t+1} \mid z^{t}\right) m_{f, t+1}\left(z_{t+1} \mid z^{t}\right) \frac{e_{t}\left(z^{t}\right)}{e_{t+1}\left(z_{t+1} \mid z^{t}\right)}
\end{aligned}
$$

This delivers the relationship between the stochastic discount factors across countries and real exchange rate dynamics discussed in Backus, Foresi, and Telmer (2001). 


\subsubsection{Firms}

The final goods firms' first-order conditions for demand of intermediate inputs from both countries determine the prices of the intermediate goods in each country in terms of the final good in that country.

$$
\frac{\partial G_{i}\left(X_{i h, t}\left(z^{t}\right), X_{i f, t}\left(z^{t}\right)\right)}{\partial X_{i j, t}\left(z^{t}\right)}=q_{i j, t}\left(z^{t}\right)
$$

The intermediate goods firms' first-order conditions imply that labor and capital are paid their marginal product:

$$
\begin{aligned}
W_{i, t}\left(z^{t}\right) & =(1-\theta) q_{i i, t}\left(z^{t}\right) K_{i, t}\left(z^{t-1}\right)^{\theta} Z_{i, t}\left(z^{t}\right)^{1-\theta} n_{i, t}\left(z^{t}\right)^{-\theta} \\
r_{i, t}\left(z^{t}\right) & =\theta q_{i i, t}\left(z^{t}\right) K_{i, t}\left(z^{t-1}\right)^{\theta-1}\left(Z_{i, t}\left(z^{t}\right) n_{i, t}\left(z^{t}\right)\right)^{1-\theta}
\end{aligned}
$$

\subsection{Terms of trade and real exchange rate}

The expressions for intermediate goods prices in equation (23) and the definition of the terms of trade in equation (12) gives the following equilibrium expressions for the terms of trade in terms of intermediate goods allocations in either country $h$ or $f$ :

$$
p_{t}\left(z^{t}\right)=\frac{1-\eta}{\eta}\left(\frac{X_{h h, t}\left(z^{t}\right)}{X_{h f, t}\left(z^{t}\right)}\right)^{\frac{1}{\sigma}}=\frac{\eta}{1-\eta}\left(\frac{X_{f h, t}\left(z^{t}\right)}{X_{f f, t}\left(z^{t}\right)}\right)^{\frac{1}{\sigma}}
$$

The equations for intermediate goods prices, the definition of the real exchange rate in equation (11), and equation (26) for the terms of trade imply the following expression which shows the equilibrium relationship between the real exchange rate and the terms of trade:

$$
e_{t}\left(z^{t}\right)=\left(\frac{(1-\eta)^{\sigma}+\eta^{\sigma}\left(p_{t}\left(z^{t}\right)\right)^{1-\sigma}}{\eta^{\sigma}+(1-\eta)^{\sigma}\left(p_{t}\left(z^{t}\right)\right)^{1-\sigma}}\right)^{\frac{1}{1-\sigma}}
$$

\subsubsection{Remaining conditions}

The remaining conditions necessary to solve for equilibrium are the laws of motion of capital (4); the law of motion of productivity (9); the relationships between intermediate goods prices across countries (10); and the market clearing conditions (15), (16), and (17). 


\section{The planner's problem}

Since international financial markets are complete, we can solve the social planner's problem for the competitive equilibrium allocations in this economy, and use the allocations to solve for prices. When households have recursive preferences as specified in equation (1) as opposed to standard additive preferences, an additional state variable is necessary to obtain a recursive value function for the planner. The formulation used here is that the planner maximizes the utility of agent $h$ subject to a constraint on the utility of agent $f$. The additional state variable is then the promised utility to agent $f, \bar{U}_{f, t}{ }^{5}$

In the recursive formulation of the problem allocations at time $t$ are only a function of the vector of state variables at time $t$ rather than the entire history. This vector is labeled $s_{t}$ and is given by

$$
s_{t}=\left(K_{h, t}, K_{f, t}, \bar{U}_{f, t}, Z_{h, t}, Z_{f, t}\right)
$$

In each period the planner chooses allocations and a promised utility to agent $f$ for each possible realization of the exogenous state variables next period. The planner's problem is then:

Given $s_{t}$, choose $C_{i, t} \geq 0, n_{i, t} \in[0,1], K_{i, t+1} \geq 0, I_{i, t} \geq 0, X_{i j, t} \geq 0$, for $i, j \in\{h, f\}$, and the function $\bar{U}_{f, t+1}\left(Z_{h, t+1}, Z_{f, t+1}\right)$ for all possible realizations of $\left(Z_{h, t+1}, Z_{f, t+1}\right)$, in order to solve

$$
Q\left(s_{t}\right)=\max \quad\left[(1-\beta)\left(C_{h, t}^{\tau}\left(1-n_{h, t}\right)^{1-\tau}\right)^{\rho}+\beta\left(\mathbb{E}\left(Q\left(s_{t+1}\right)^{\alpha} \mid s_{t}\right)\right)^{\rho / \alpha}\right]^{1 / \rho}
$$

subject to

$$
\left[(1-\beta)\left(C_{f, t}^{\tau}\left(1-n_{f, t}\right)^{1-\tau}\right)^{\rho}+\beta\left(\mathbb{E}\left(\bar{U}_{f, t+1}\left(Z_{h, t+1}, Z_{f, t+1}\right)^{\alpha} \mid s_{t}\right)\right)^{\rho / \alpha}\right]^{1 / \rho} \geq \bar{U}_{f, t}
$$

+ the laws of motion for capital and productivity in equations (4) and (9), and the market clearing conditions for final and intermediate goods in equations (16) and (17). For notational convenience the dependence of all the choice variables on the state $s_{t}$ is captured by writing variable $X\left(s_{t}\right)$ as $X_{t}$ in the formulation above. Note that since preferences exhibit non-satiation we can assume that constraint (29) holds with equality at the optimum. The utility obtained by agent $f$ is then given by $U_{f}\left(s_{t}\right)=\bar{U}_{f, t}, \forall t$.

\subsection{Solving the planner's problem}

In the solution to the planner's problem there are two conditions that are of particular interest. First, the ratio of the first-order conditions with respect to the consumptions of

\footnotetext{
${ }^{5}$ For an alternative formulation of a recursive planner's problem see Colacito and Croce (2011b,c). They solve a similar problem as proposed by Jr. and Stokey (1984) and Kan (1995).
} 
the two agents implies the following condition for the planner's allocations of consumption across the two countries:

$$
\lambda^{*}\left(s_{t}\right)\left(\frac{C_{f}\left(s_{t}\right)}{C_{h}\left(s_{t}\right)}\right)^{\tau \rho-1}\left(\frac{1-n_{f}\left(s_{t}\right)}{1-n_{h}\left(s_{t}\right)}\right)^{(1-\tau) \rho}=\frac{\lambda_{C f}\left(s_{t}\right)}{\lambda_{C h}\left(s_{t}\right)}
$$

The term $\lambda^{*}$ is the ratio of Pareto weights that determines how the planner allocates goods across countries, and $\lambda_{C i}$ for $i \in\{h, f\}$ are the lagrange multipliers on the resource constraints for the final goods in (16).

We let $\lambda_{U}\left(s_{t}\right)$ be the lagrange multiplier on the planner's promise-keeping constraint (29), and $\lambda^{*}\left(s_{t}\right)$ is defined as

$$
\lambda^{*}\left(s_{t}\right)=\lambda_{U}\left(s_{t}\right)\left(\frac{U_{f}\left(s_{t}\right)}{U_{h}\left(s_{t}\right)}\right)^{1-\rho}
$$

The Pareto weight on agent $h$ is then given by $\mu^{*}\left(s_{t}\right)$ where

$$
\mu^{*}\left(s_{t}\right)=\frac{1}{1+\lambda^{*}\left(s_{t}\right)} \quad \text { or } \quad \lambda^{*}\left(s_{t}\right)=\frac{1-\mu^{*}\left(s_{t}\right)}{\mu^{*}\left(s_{t}\right)}
$$

and the Pareto weight on agent $f$ is $1-\mu^{*}\left(s_{t}\right)$. Equation (31) implies that there is a oneto-one mapping between the continuation utility state variable $\bar{U}_{f, t}$ and the Pareto weight ratio $\lambda^{*}\left(s_{t}\right)$. We therefore consider the optimal allocations functions of $\lambda^{*}$ and discuss the dynamics of the model in terms of the dynamics of this ratio.

The second condition of particular interest governs the dynamics of the Pareto weight ratio. For a given realization of the productivity shocks next period the first-order condition with respect to $\bar{U}_{f}\left(s_{t+1}\right)$, the envelope condition with respect to $\bar{U}_{f, t}$, and the definition of $\lambda^{*}\left(s_{t}\right)$ imply

$$
\frac{\lambda^{*}\left(s_{t+1}\right)}{\lambda^{*}\left(s_{t}\right)}=\left(\frac{U_{h}\left(s_{t+1}\right)}{\zeta_{t}\left(U_{h, t+1}\right)}\right)^{\rho-\alpha}\left(\frac{U_{f}\left(s_{t+1}\right)}{\zeta_{t}\left(U_{f, t+1}\right)}\right)^{\alpha-\rho}
$$

\subsubsection{Allocations from the planner's problem}

In the case where $\alpha=\rho$, the model reduces to the standard model where agents have additive expected utility preferences. Equation (33) shows that the Pareto weight ratio is constant in that case. It is then common to set the Pareto weight on each country to $1 / 2$ so that $\lambda^{*}\left(s_{t}\right)=1 \forall t$. Therefore it is not crucial to emphasize how allocations depend on this ratio, and the dependence can be left implicit. 
In contrast when $\alpha<\rho$ and agents have recursive preferences, ${ }^{6}$ the dynamics of $\lambda^{*}$ reflect a key feature of the efficient allocations: Shocks not only affect the contemporaneous allocations of consumption and leisure, but also agents' continuation utilities. As discussed below, the response in the continuation utilities will also be reflected in prices in the decentralized equilibrium, and will therefore imply that the response in the real exchange rate is partially disconnected from the responses in consumption and leisure across countries.

The change in the Pareto weight ratio after a shock at time $t+1$ is given by equation (33). As the equation shows, the change is related to the continuation utility of each agent relative to that agent's certainty equivalent. The terms $U_{i}\left(s_{t+1}\right) / \zeta_{t}\left(U_{i, t+1}\right)$ can be thought of as innovations in the agents' future utilities, and changes in $\lambda^{*}$ reflect differences in these innovations. For shocks to imply dynamics that are very different from the case with additive preferences they therefore have to have different long-run implications for the two countries. Such shocks imply differences in continuation utilities which are reflected in the dynamics of the Pareto weight ratio.

Consider for example a positive productivity shock in country $h$. This leads to an increase in the production of intermediate good $h$. Since both agents derive utility from final goods that are produced with intermediate good $h$ as an input, the planner can increase the utility of both agents by increasing allocations of intermediate good $h$. Both innovations in future utility are therefore greater than 1 . However, due to home bias the planner increases the consumption of agent $h$ more. The production of final good $h$ uses intermediate good $h$ more intensively and therefore increases more than the production of final good $f$. The innovation in the utility of agent $h$ is therefore larger than the innovation in the utility of agent $f$. Agent $h$ benefits more when productivity increases for the good that he is biased towards.

Since $\alpha<\rho$, equation (33) shows that a positive productivity shock in country $h$ which leads to a larger innovation in the future utility of agent $h$, also leads to an increase in the Pareto weight ratio. The planner increases the Pareto weight on agent $f$ to partially compensate him for the productivity shock that is relatively less favorable for him. The changes in the Pareto weight ratio thus reflect the agents' desire to smooth future utility.

\section{$3.2 \quad$ Allocations and prices}

In the decentralized equilibrium the dynamics of the allocations reflected in the variation of the Pareto weight ratio correspond with trade in state-contingent securities. The agents partially insure each other against relatively bad productivity shocks. The price of these securities is determined by agents' stochastic discount factors in equation (20). It is common in the literature on recursive preferences to decompose the stochastic discount factors into

\footnotetext{
${ }^{6}$ When $\alpha<\rho$ agents prefer early resolution and low persistence of uncertainty. We restrict our attention to this case which is considered most relevant in the literature.
} 
a "short-run component" $(S R C)$ and a "long-run component" $(L R C)$ (see for example Kaltenbrunner and Lochstoer (2010)), as follows:

$$
m_{i}\left(s_{t+1}, s_{t}\right)=\underbrace{\beta\left(\frac{C_{i}\left(s_{t+1}\right)}{C_{i}\left(s_{t}\right)}\right)^{\tau \rho-1}\left(\frac{1-n_{i}\left(s_{t+1}\right)}{1-n_{i}\left(s_{t}\right)}\right)^{(1-\tau) \rho}}_{S R C_{i}\left(s_{t+1}, s_{t}\right)} \underbrace{\left(\frac{U_{i}\left(s_{t+1}\right)}{\zeta_{t}\left(U_{i, t+1}\right)}\right)^{\alpha-\rho}}_{L R C_{i}\left(s_{t+1}, s_{t}\right)}
$$

The dynamics in the Pareto weight ratio therefore correspond to heterogeneous responses to productivity shocks in the long-run components of the stochastic discount factors.

This will also be reflected in movements in the real exchange rate. One way to see this is through equation (22). Taking logs of that equation we obtain:

$$
\Delta \log e\left(s_{t+1}\right)=\log m_{f}\left(s_{t+1}, s_{t}\right)-\log m_{h}\left(s_{t+1}, s_{t}\right)
$$

Continuing the example from above, a positive productivity shock in country $h$ leads to a larger innovation in future utility in country $h$. With $\alpha<\rho$ the resulting drop in $m_{h}$ is larger than the drop in $m_{f}$, and the real exchange rate depreciates.

Another way to see the connection between the dynamics of the Pareto weight ratio in the planner's problem and movements in the real exchange rate in the decentralized equilibrium, is through equation (30). The ratio of lagrange multipliers on the resource constraints for final goods in the planner's problem, $\lambda_{C f} / \lambda_{C h}$ correspond to the real exchange rate in the decentralized equilibrium. Thus equation (30) can be written:

$$
\lambda^{*}\left(s_{t}\right)\left(\frac{C_{f}\left(s_{t}\right)}{C_{h}\left(s_{t}\right)}\right)^{\tau \rho-1}\left(\frac{1-n_{f}\left(s_{t}\right)}{1-n_{h}\left(s_{t}\right)}\right)^{(1-\tau) \rho}=e\left(s_{t}\right)
$$

Dynamics in the Pareto weight ratio therefore imply that the model delivers real exchange rate movements that are partially disconnected from relative movements in consumption and leisure. To evaluate whether this implies that the model can explain the high variability of the real exchange rate in the data, we solve the model numerically.

\subsection{Balanced growth and restricting the cointegrating vector}

Since $\log Z_{h, t}\left(z^{t}\right)$ and $\log Z_{f, t}\left(z^{t}\right)$ are both integrated processes we need to normalize the equilibrium conditions to obtain a stationary system. The country $i$ variables that have a trend are rescaled by dividing through by the level of productivity in country $i, Z_{i, t}\left(z^{t}\right) .^{7}$ The full set of normalized equations are presented in appendix (A).

\footnotetext{
${ }^{7}$ There are two exceptions to this: $(i)$ the utilities of the households $U_{i, t}\left(z^{t}\right)$ are divided by $Z_{i, t}\left(z^{t}\right)^{\tau}$ because there is a trend in consumption, but not in leisure, and (ii) the capital stocks $K_{i, t}\left(z^{t-1}\right)$ are divided by $Z_{i, t-1}\left(z^{t-1}\right)$ so that the normalized capital stock is determined at the start of period $t$.
} 
This model satisfies the restrictions on the production function and preferences from King, Plosser, and Rebelo (1988) that are necessary for the existence of a balanced growth path. Along with a productivity process with a unit root these conditions are also sufficient in a closed economy, but as discussed in Rabanal et al. (2011), a two-country model requires an additional restriction on the cointegrating vector to ensure balanced growth. The restriction is that the ratio of productivities $Z_{h}\left(s_{t}\right) / Z_{f}\left(s_{t}\right)$ must be stationary.

To see the need for this additional restriction consider for example the normalized version of equation (30):

$$
\lambda^{*}\left(s_{t}\right) \tilde{z}\left(s_{t}\right)^{1-\tau \rho}\left(\frac{c_{f}\left(s_{t}\right)}{c_{h}\left(s_{t}\right)}\right)^{\tau \rho-1}\left(\frac{1-n_{f}\left(s_{t}\right)}{1-n_{h}\left(s_{t}\right)}\right)^{(1-\tau) \rho}=e\left(s_{t}\right)
$$

where $c_{i}\left(s_{t}\right)$ are rescaled consumptions, and $\tilde{z}\left(s_{t}\right)=Z_{h}\left(s_{t}\right) / Z_{f}\left(s_{t}\right)$. Since the real exchange rate and labor supply in each country are stationary, if the ratio $\tilde{z}\left(s_{t}\right)$ was non-stationary then either the ratio of consumptions or the ratio of Pareto weights would be non-stationary. In either case balanced growth would not exist. A sufficient condition for stationarity of $\tilde{z}\left(s_{t}\right)$ is that the cointegrating vector in the law of motion for productivity $(9)$ is $(1,-1)$. That is, we require that $\kappa=1$.

\subsection{Solution method}

Heathcote and Perri (2002) and Rabanal et al. (2011) respectively linearize and log-linearize their models and compute moments by averaging across simulations. Here we follow a similar procedure, but to adequately capture the dynamics in this model a higher-order approximation is necessary. The reason is that the parameter $\alpha$ does not appear in a firstorder approximation around a deterministic steady state. As shown in equation (33) the difference between $\alpha$ and $\rho$ is key in determining the dynamics of the Pareto weights, so a good approximation of the effect of $\alpha$ on the dynamics of the model is necessary. In a second-order approximation $\alpha$ only shows up in the constant terms. Hence, we use a third-order approximation to capture the impact of $\alpha{ }^{8,9}$

\section{Parameterization and results}

The parameter values we use in our benchmark are reported in table 1.

\footnotetext{
${ }^{8}$ See van Binsbergen et al. (2008) for a discussion of the application of perturbation methods to models with recursive preferences. See Colacito and Croce (2011c) for a discussion of the need for a third-order approximation to capture the dynamics in an endowment economy with risk-sensitive agents.

${ }^{9}$ The coefficients of the third-order approximation are easily computed using Dynare ++ , which can also compute approximations of a higher order. It is therefore straightforward to check that our results are not substantially affected by using an approximation of a higher order.
} 


\subsection{Key parameters}

Two parameters that play a key role in driving our results are the degree of risk aversion over the consumption-leisure composite $1-\alpha$, and the elasticity of substitution between the two intermediate goods $\sigma$.

The value of risk aversion is set either to 2 which implies that agents have the additive preferences used by Rabanal et al., or it is set to 100 which follows the literature using Epstein-Zin preferences in production economies to match asset pricing facts. ${ }^{10}$ As is common to that literature, a large value of risk aversion is necessary to generate sufficient volatility in the stochastic discount factors in a frictionless model with complete markets where the only source of risk is shocks to productivity.

There are two important points to note regarding this choice. First, as discussed in section 2.2, the measure of risk aversion consumption is given by $\tau(1-\alpha)$ since utility is also a function of leisure. Second, Barillas et al. (2008) and Bidder and Smith (2012) argue that such large values of risk aversion can be reinterpreted as plausible fears of model misspecification in endowment and production economies respectively.

Following a common practice in the recent literature on international macroeconomics, the trade elasticity is set to the low value of $\sigma=0.6$. Examples of papers using a value well below 1 are Heathcote and Perri (2002) $(\sigma=0.9)$, Corsetti, Dedola, and Leduc (2008) $(\sigma=0.5)$, Raffo (2009) $(\sigma=0.5)$, and Rabanal et al. $(2011)(\sigma=0.62$ or $=0.85) .{ }^{11} \mathrm{~A}$ choice of $\sigma$ imposes a corresponding choice of the home bias parameter $\eta$, since together these parameters determine the import ratio in the deterministic steady state. The parameters for the productivity process (discussed below) are based on estimates by Rabanal et al. who use data for the period 1973Q1-2006Q4. We therefore choose $\eta$ to match the import ratio in the United States of about $12 \%$ in that period. That is, $\eta$ solves the equation

$$
0.12=\left(\frac{1-\eta}{\eta}\right)^{\sigma}
$$

Since the combination of parameters $(\sigma, \eta)$ that fit this import ratio is key to the mechanism proposed in this paper, we investigate the sensitivity of the results to the choice of these values in section 5.1 .

\subsection{Other parameters}

The rest of the parameter choices follow Rabanal et al. (2011) who generally use values that are standard in the international macroeconomics literature. ${ }^{12}$ The discount factor $\beta$ is set

\footnotetext{
${ }^{10}$ See for example van Binsbergen et al. (2010), Rudebusch and Swanson (2011), and Andreasen (2011).

${ }^{11}$ Note that since the model features complete financial markets it does not suffer from the potential of multiple equilibria as discussed in Bodenstein (2010) despite a low value for $\sigma$.

${ }^{12}$ They closely follow papers such as Heathcote and Perri (2002) and Backus et al. (1992, 1994).
} 


\begin{tabular}{lll} 
Benchmark parameters & \\
\hline Preferences & Discount factor & $\beta=0.99$ \\
& Consumption share & $\tau=0.34$ \\
& Intertemporal elasticity of substitution & $1 /(1-\rho)=0.5$ \\
& Risk aversion & $1-\alpha=2$ or $1-\alpha=100$ \\
& & \\
Technology & E.o.s. between intermediate goods & $\sigma=0.6$ \\
& Import ratio & $0.12(\Rightarrow \eta=0.972)$ \\
& Capital share & $\theta=0.36$ \\
Depreciation rate & $\delta=0.025$ \\
& Productivity VECM & $\phi_{0 h}=\phi_{0 f}=0.0036$ \\
& $\phi_{1 h}=-0.007, \phi_{1 f}=0.007, \kappa=1$ \\
& Standard deviation of innovations & $\sigma_{\varepsilon}=0.0105$ \\
\hline
\end{tabular}

Table 1: Benchmark parameters: In the additive preferences case we set $1-\alpha=2$. In the recursive preferences case we set $1-\alpha=100$.

to .99. The consumption share in the consumption-leisure composite $\tau$, is set to 0.34 . The intertemporal elasticity of substitution $1 /(1-\rho)$ is set equal to 0.5 . Standard values are also used for the other technology parameters. The capital share in production $\theta$, is set to 0.36 , and the depreciation rate $\delta$ is set to 0.025 .

The parameters of the VECM for productivity are set based on the estimates in Rabanal et al. They construct series for labor augmenting TFP for the United States and the "rest of the world" where the latter is an aggregate consisting of the Euro area plus the United Kingdom, Canada, Japan and Australia. They use data on real GDP, hours, employment and real capital stocks. The key result from their estimates are that they cannot reject the hypothesis that the TFP series are cointegrated with a cointegrating vector equal to $(1,-1)$. Hence, $\kappa=1$ and the restriction required for balanced growth is satisfied. A second important result is that the coefficients for the speed of adjustment are significant, but small. This implies that the TFP processes converge slowly over time and that differences in productivity across countries are persistent. Consistent with their estimates we set $\phi_{1 h}=-0.007$ and $\phi_{1 f}=0.007$.

We impose a symmetric productivity process across the two countries and set $\phi_{0 h}=\phi_{0 f}=$ 0.0036. In Rabanal et al. these estimates differ, but due to cointegration the TFP processes nevertheless grow at the same rate along the balanced growth path. Their estimates imply an annualized long-run growth rate of TFP of 1.44 percent which is also the implication from our choice of parameters. Finally we set the standard deviation of the innovations to the productivity processes to 0.0105 which is the estimate from Rabanal et al. for the United States. 


\subsection{Deterministic vs. stochastic steady state}

It is important to note that since we solve the model with a third-order approximation, certainty equivalence does not hold. Therefore the deterministic steady state does not correspond to the mean of the ergodic distribution of the variables in the model. To obtain an approximation to this mean, we start our economy at the deterministic steady state and "simulate" the economy under a sequence of productivity shocks set equal to zero. The economy converges to a point which we refer to as the stochastic steady state, where agents take into account the uncertainty in the economy. They therefore work more and invest more to maintain a higher capital stock, which lowers the return on capital. In our simulations and impulse response functions we use the stochastic steady state as our starting point. ${ }^{13}$

\subsection{Results for the benchmark parameters}

As the model is non-stationary we follow the approach of Rabanal et al. and compute HPfiltered moments by stochastic simulation. The model is simulated for 125 periods starting from the stochastic steady state, and the HP-filter is applied to the series for output, consumption, investment, employment and the real exchange rate. Second moments are computed from the filtered series, and the averages over 100 simulations are reported in table 2. ${ }^{14}$ The first and second rows of each panel in table 2 report the results for the economy with additive and recursive preferences respectively. With additive preferences the model discussed here is a complete markets version of the economy in Rabanal et al., and the results are similar to the results they report for that case.

Extending the standard model to allow for recursive preferences improves the model's ability to match the volatility of the real exchange rate relative to output. For the benchmark parameters the striking result is that the model with recursive preferences explains more than $95 \%$ while the model with additive preferences only explains about $35 \%$ of the relative real exchange rate volatility.

As in Tallarini (2000) the model also generates a high market price of risk when preferences are recursive and risk aversion is high. The market price of risk in the model is about $21 \%$ which is slightly lower than the $25 \%$ that Tallarini finds in the data. ${ }^{15}$ Table 3 reports the market price of risk for the model with additive and recursive preferences. In addition it

\footnotetext{
${ }^{13} \mathrm{An}$ alternative approach is to start simulations at the deterministic steady state, but discard a large number of periods at the start of each simulation as a burn-in. See for example van Binsbergen et al. (2008). We find that using this approach does not affect our results.

${ }^{14}$ For some of our parameterizations we have also computed averages over 1000 simulations and found that this does not affect the results.

${ }^{15}$ Tallarini (2000) calculates the market price of risk from U.S. data from $1948: 2-1993: 4$. The data used are the value-weighted NYSE portfolio and the 3-month Treasury bill.
} 
Results - additive and recursive preferences

\begin{tabular}{lllllll}
\hline & $\operatorname{sd}(y)$ & $\operatorname{rsd}(c)$ & $\operatorname{rsd}(\iota)$ & $\operatorname{rsd}(n)$ & $\operatorname{rsd}(e)$ & $\rho(e)$ \\
\hline Data & 1.58 & 0.76 & 4.55 & 0.75 & 3.06 & 0.82 \\
\hline Additive & 0.85 & 0.71 & 2.27 & 0.21 & 1.16 & 0.73 \\
Recursive & 0.74 & 0.67 & 2.20 & 0.24 & 2.96 & 0.70
\end{tabular}

\begin{tabular}{llllll} 
& \multicolumn{2}{l}{ Correlations } & \\
\cline { 2 - 5 } & $(y, n)$ & $(y, c)$ & $(y, \iota)$ & $(y, n x)$ & $\left(e, c_{h} / c_{f}\right)$ \\
\hline Data & 0.87 & 0.84 & 0.91 & -0.49 & -0.04 \\
\hline Additive & 0.96 & 0.99 & 0.98 & -0.61 & 1.00 \\
Recursive & 0.96 & 0.99 & 0.97 & -0.48 & 1.00
\end{tabular}

\begin{tabular}{lllll} 
& \multicolumn{4}{l}{ Correlations } \\
\cline { 2 - 5 } & $\left(y_{h}, y_{f}\right)$ & $\left(c_{h}, c_{f}\right)$ & $\left(\iota_{h}, \iota_{f}\right)$ & $\left(n_{h}, n_{f}\right)$ \\
\hline Data & 0.44 & 0.36 & 0.28 & 0.40 \\
\hline Additive & 0.24 & 0.19 & -0.14 & 0.29 \\
Recursive & 0.52 & 0.65 & 0.12 & 0.22 \\
\hline
\end{tabular}

Table 2: Second moments from HP-filtered simulated series: 'sd' denotes standard deviation; 'rsd' denotes standard deviation relative to output; $(y, c, \iota, n, e, n x)$ are respectively output, consumption, investment, labor, the real exchange rate, and net exports; ' $\rho$ ' denotes first-autocorrelation. Moments are calculated as the average over 100 simulations of 125 periods. 
reports the standard deviation of the stochastic discount factor, and the standard deviations of the short-run and long-run components of the stochastic discount factor.

The results show that the model with additive preferences does not come close to matching the market price of risk. With additive preferences $\alpha=\rho$ and the stochastic discount factor consists of the short-run component only. Since the variability of this component is low, so is the market price of risk. With recursive preferences on the other hand, the variability of the stochastic discount factor is high, and this is mainly driven by the variability of the long-run component. Since there is a unit root in the process for productivity, technology shocks have permanent effects. They therefore produce large innovations in future utility and hence, a high volatility of the stochastic discount factors.

\begin{tabular}{lllcc} 
Parameterization & $\mathrm{MPR}$ & $\mathrm{sd}(m)$ & $\mathrm{sd}(S R C)$ & $\mathrm{sd}(L R C)$ \\
\hline Additive & 0.58 & 0.57 & 0.57 & 0.00 \\
Recursive & 20.8 & 20.5 & 0.41 & 20.1 \\
\hline
\end{tabular}

Table 3: 'MPR' denotes the market price of risk, $100 s d(m) / \mathbb{E}(m)$; ' $m$ ' denotes the stochastic discount factor; ' $S R C$ ' denotes the short-run component and ' $L R C$ ' denotes the long-run component; 'sd' denotes the standard deviation. Each term is calculated as the average over 100 simulations of 125 periods.

\subsubsection{Productivity shocks and optimal allocations}

To analyze the dynamics that deliver the results discussed above, we first consider how the optimal allocations in this economy respond to productivity shocks. Figures 1 and 2 plots simple impulse response functions to a one standard deviation shock to productivity in country $h$. The impulse responses are plotted for the model with additive preferences (dashed red line) and the model with recursive preferences (solid blue line).

The responses in the quantities in the two models broadly follow the same pattern. A positive technology shock in country $h$ has a permanent effect on productivity there, while the productivity in country $f$ is expected to catch up in the long-run due to cointegration. In the short-run there is therefore a difference in the levels of productivity in the two countries. In country $h$ the response is that GDP, investment, labor supply, and consumption increase. Greater supply of intermediate good $h$ leads to an increase in the terms of trade. The increase in the relative price of intermediate good $f$ leads to immediate increases in GDP, labor supply and consumption in that country as well. The initial responses in country $f$ are smaller, but productivity growth is higher and brings productivity in country $f$ to its new long-run growth path. As the cross-country difference in the level of technology is gradually eliminated, GDP, investment and consumption increase further. In country $h$ on the other hand, cointegration implies that following the shock productivity growth is lower than along the balanced growth path. Thus investment is temporarily higher than its new long-run level and there is a hump-shaped response in consumption and GDP. 
Despite the broadly similar patterns in the models with additive and recursive preferences, there are important differences between them. First, the models produce different responses in investment in country $f$. In both models investment increases over time in country $f$ as productivity increases, but in the model with additive preferences investment initially drops. This leads to a negative correlation in investment across countries in that model. In the model with recursive preferences on the other hand, investment in country $f$ increases in response to the shock. That model therefore produces the positive cross-country correlation of investment that we see in the data.

Second, and more important, are the differences in the magnitudes of the responses described above. To see how these differences arise, consider the planner's problem of allocating resources between the two countries. The planner chooses how much of each intermediate good is produced and how the total produced of each intermediate input is allocated to be used for consumption and investment. The share of intermediate good $i \in\{h, f\}$ allocated to households in country $h$ at time $t$ is defined as

$$
\operatorname{share}_{h i, t}=\frac{X_{h i, t}}{X_{h i, t}+X_{f i, t}}
$$

and the corresponding shares to households in country $f$ are given by share ${ }_{f i, t}=1$ - share $_{h i, t}$. Figure 3 plots simple impulse responses for the total production of each intermediate good and the share of each good allocated to each agent.

The differences between the two models are clear from the plots in figure 3 . In both cases the planner chooses virtually the same response in production of intermediate goods, but the allocation of those goods depends on agents' preferences. When households have additive preferences, the planner temporarily increases the shares of both intermediate goods allocated to country $h$. As shown in figure 2, this allows for a relatively larger increase in investment and consumption in country $h$. Resources therefore move to the country where productivity is temporarily higher. When agents have recursive preferences on the other hand, the planner reduces the shares of each intermediate good allocated to agent $h$ and increases the shares to agent $f$. The response in consumption and investment in country $h$ is therefore lower, and households work more. For households in country $f$ the larger shares they receive in the model with recursive preferences allow consumption and investment to increase more and they work less.

The relatively larger share of resources allocated to country $f$ in the model with recursive preferences is reflected in the drop in the Pareto weight on country $h, \mu^{*}$. When households have recursive preferences, they dislike fluctuations in future utility as well as fluctuations in consumption and leisure. The planner therefore aims to smooth continuation utility across states in the future. Due to home bias however, the planner does not choose to equalize continuation utility across states. When productivity increases in country $h$ there is relatively more of intermediate good $h$ being produced. Since households in $h$ consume the final good produced using intermediate good $h$ as the main input, it is easier for the planner to provide utility to those households. Given the productivity realization the utility 
of those households therefore increase more. This heterogeneous response across countries is reflected in the increase in the Pareto weight ratio as shown by equation (33). The increase in the Pareto weight on households in country $f$ compensates for the shock to productivity that is lower domestically than abroad, and increases the share of available intermediate goods they receive.

\subsubsection{Variability in real exchange rates}

The dynamics in the optimal allocations described above is supported by corresponding price dynamics in the decentralized equilibrium. As discussed in section 3.1, heterogeneous innovations to future utility that arise due to home bias and are reflected in the dynamics of the Pareto weights, can also amplify the response of the real exchange rate. Figure 1 shows that this is indeed the case in the baseline parameterization of the model.

Another way to see that home bias is essential for generating real exchange rate volatility, is through equation (27) which shows how the real exchange rate relates to the terms of trade. Clearly, if $\eta=1 / 2$ so that there is no home bias, then the real exchange rate is constant even when the terms of trade increase. With home bias on the other hand, real exchange rate volatility corresponds with volatility in the terms of trade.

Figure 6 in appendix B shows impulse responses in the intermediate goods prices, the terms of trade and the real exchange rate after a one standard deviation shock to productivity in country $h$. The shock leads to a persistent increase in the supply of intermediate good $h$ relative to intermediate good $f$. In the model with recursive preferences the persistent increase leads to a larger relative increase in the marginal utility of consumption in country $f$ which increases the real exchange rate. This corresponds with a larger increase in the equilibrium terms of trade which induces final goods firms in country $h$ to reduce their demand of intermediate good $f$ and to increase their demand for intermediate good $h$ by less than the increase in production. Hence, the share of both intermediate goods used in final goods production in country $h$ is reduced.

In country $f$ the larger increase in the price of the domestically produced intermediate good in the model with recursive preferences imply that the wage and the rental rate of capital increase more in that model. Impulse responses for wages and rental rates are shown in figure 5 in appendix B. In addition, the change in the Pareto weight corresponds with the payoff of assets purchased by households in country $f$ from households in country $h$. Households thereby insure each other against a relatively worse realization of the productivity shock. The larger wealth effect in the model with recursive preferences allow households in that model to increase consumption and leisure more, and accounts for the positive response in investment, as seen in figure 2 . 

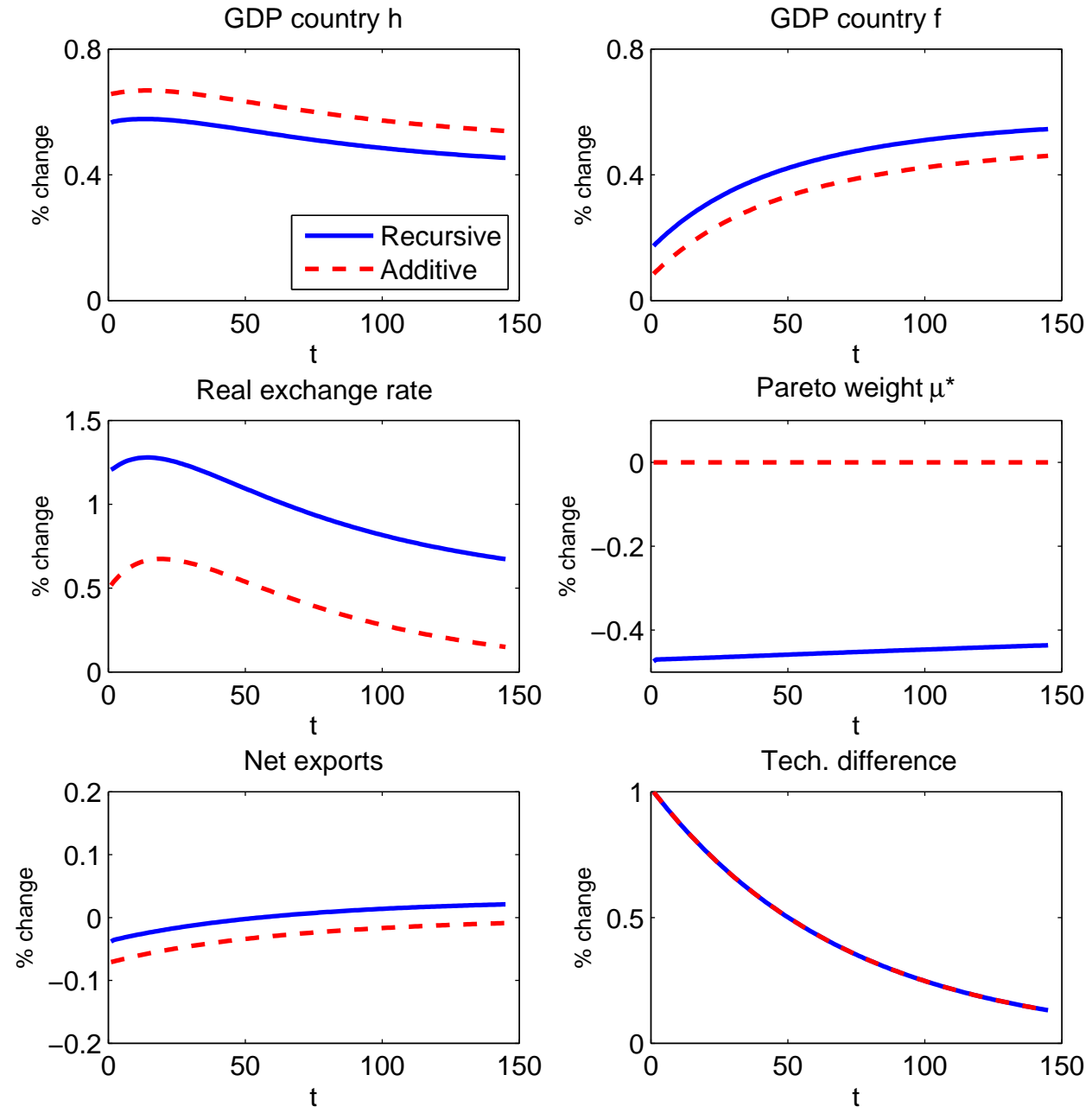

Figure 1: Impulse responses functions after a one standard deviation shock to productivity in country $h$. The impulse responses are plotted as percentage difference from the balanced growth path for the model with additive preferences $(1-\alpha=2)$ and with recursive preferences $(1-\alpha=100)$. 

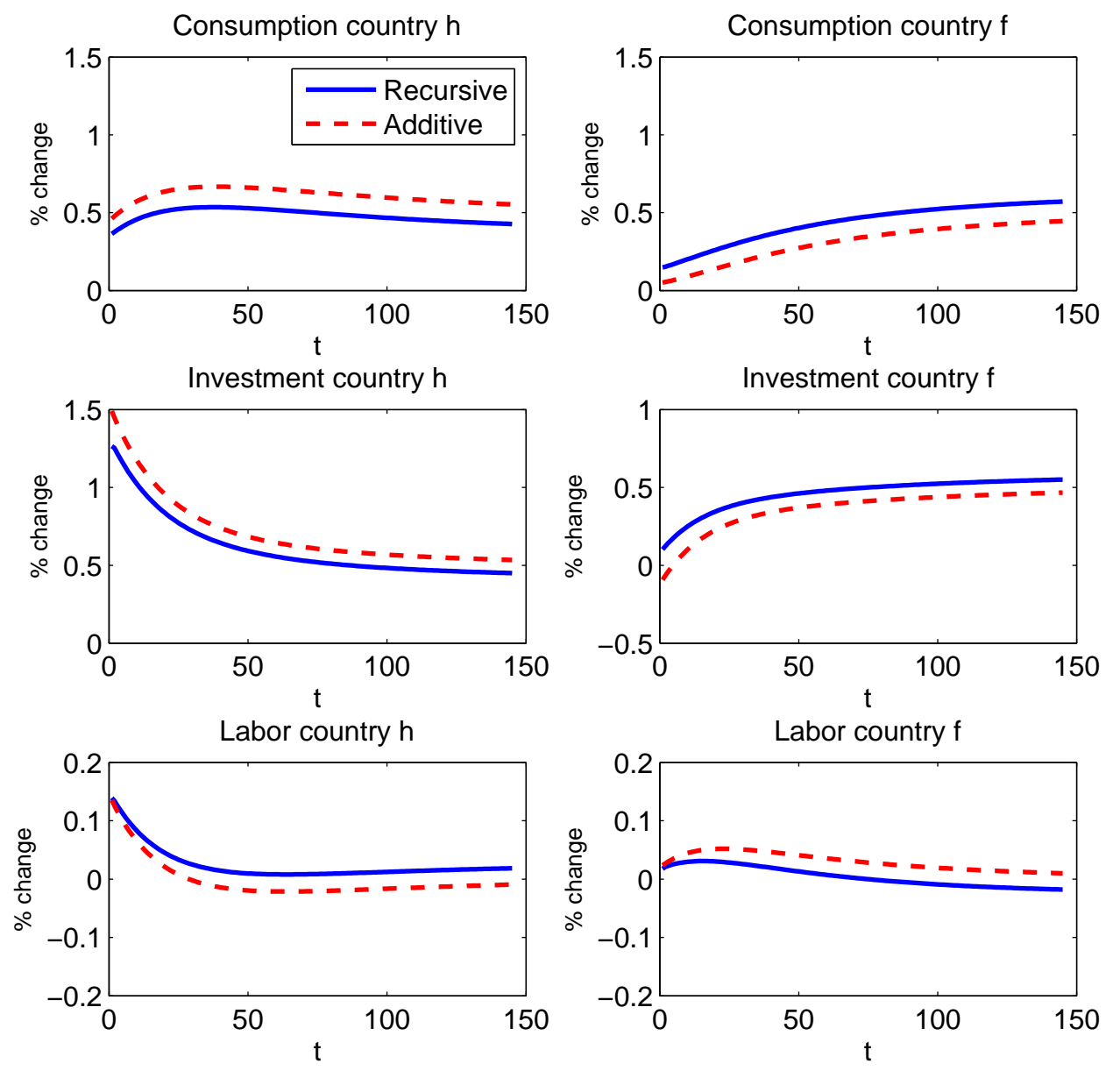

Figure 2: Impulse responses functions after a one standard deviation shock to productivity in country $h$. The impulse responses are plotted as percentage difference from the balanced growth path for the model with additive preferences $(1-\alpha=2)$ and with recursive preferences $(1-\alpha=100)$. 

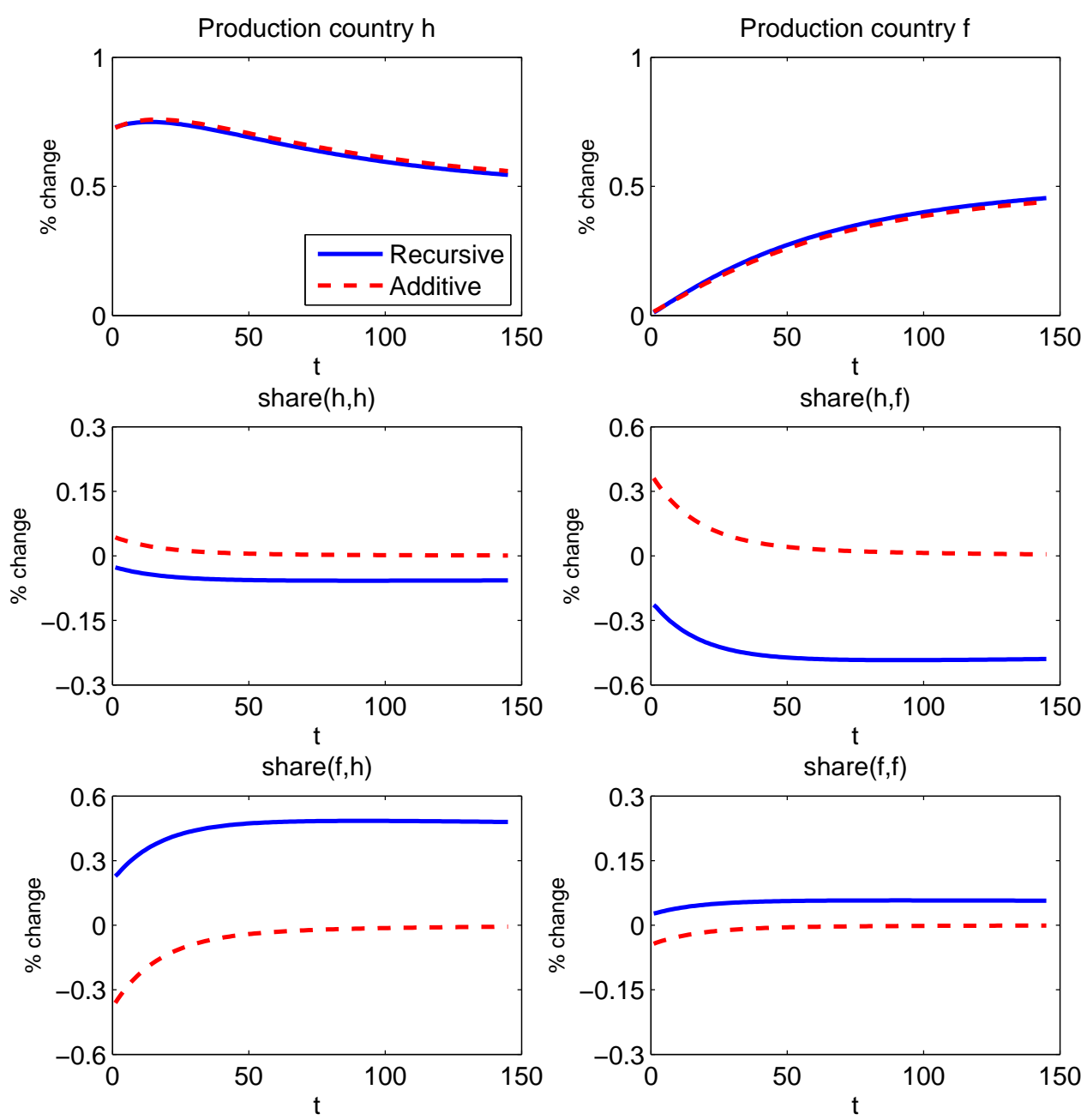

Figure 3: Impulse responses functions after a one standard deviation shock to productivity in country $h$. The impulse responses are plotted as percentage difference from the balanced growth path for the model with additive preferences $(1-\alpha=2)$ and with recursive preferences $(1-\alpha=100)$. The top panels show the total production of intermediate goods in the two countries. 'share $(i, j)$ ' denotes the share of intermediate good $j$ allocated to country $i$. 


\subsubsection{Comovements and remaining puzzles}

As argued above and shown in table 2, the model with recursive preferences leads to positive comovement of employment and investment across countries as in the data. In addition, this model closely matches the countercyclicality of net exports. However, this occurs due to the amplified response in relative prices. As shown in figure 3 a productivity shock in country $h$ reduces the share of intermediate good $f$ allocated to country $h$. Since the production of that good has not yet increased, the reduced share corresponds with a fall in the quantity shipped. The fact that net exports still fall is due to the large increase in the terms of trade. ${ }^{16}$

The risk-sharing that takes place in the model with recursive preferences leads consumption in the model to more correlated across countries than in the data. The cross-country correlation in consumption is also higher than the cross-country correlation in output in the model. The standard "quantity puzzle" is therefore left unaccounted for. In addition, the amplified real exchange rate movements that the model produces correspond with a relatively larger increase in consumption in the country hit with a productivity shock. The correlation between the real exchange rate and the ratio of consumption across countries is therefore also equal to 1 in the baseline model with recursive preferences. ${ }^{17}$ The model therefore cannot account for the "Backus-Smith" puzzle (Backus and Smith, 1993).

\subsection{A note on survival}

An issue that arises in this economy due to the dynamics in the Pareto weights is whether a non-degenerate stationary distribution of these weights exists. Anderson (2005) finds that in a one-good endowment economy where agents have risk-sensitive preferences, dynamics in the Pareto weights only arises when agents have different degrees of risk-sensitivity. In that case a non-degenerate distribution of Pareto weights does not exist. Colacito and Croce (2011c) obtain dynamics in the Pareto weights in a two-good endowment economy where agents have risk-sensitive preferences over an aggregate consumption good. The consumption good is produced from two intermediate goods with home bias in the aggregation. Colacito and Croce prove there is a non-degenerate distribution of Pareto weights in their economy.

In the economy presented here, the dynamics in Pareto weights are partly due to the mechanism discussed by Colacito and Croce. We cannot apply their proof however, since our specification of preferences is more general and since our economy includes production and endogenous labor supply. Production introduces a separate channel that generates

\footnotetext{
${ }^{16}$ Raffo (2008) argues that countercyclical net exports should be generated by changes in the net flow of goods rather than terms of trade movements.

${ }^{17}$ With recursive preferences this is not the case for all parameter values. That model can produce a correlation less than 1 in some cases (for example if labor supply is exogenous).
} 


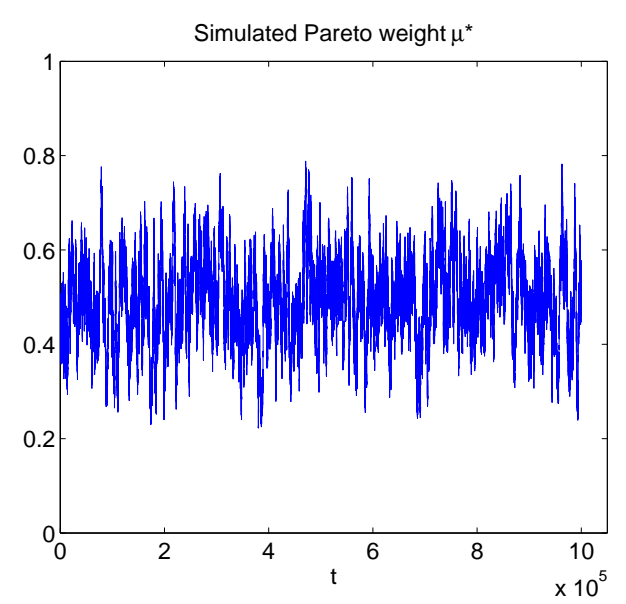

(a) Simulated Pareto weight $\mu^{*}$

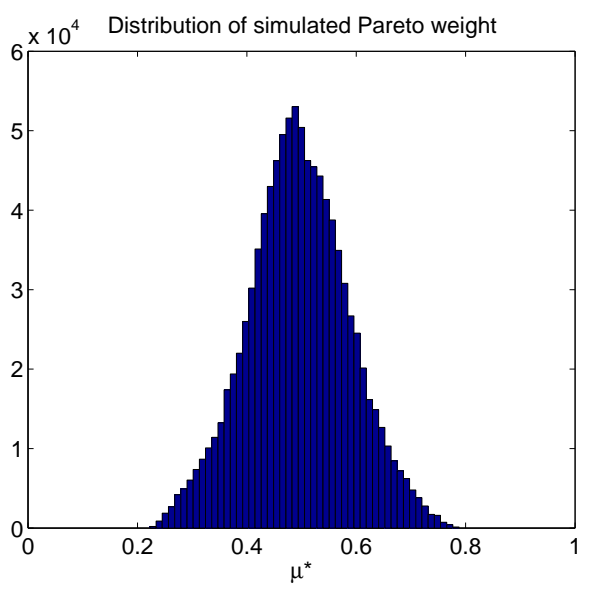

(b) Distribution of simulated Pareto weight

Figure 4: Dynamics of $\mu^{*}$ in a simulation for 1 million periods from the model with $1-\alpha=100$.

dynamics in the Pareto weights. Even in a production economy with a single good and no heterogeneity in preference parameters the Pareto weights will change over time. The reason is that different realizations of productivity shocks will induce different optimal labor supply decisions across agents. Hence, heterogeneity in agents' utilities from consumption can arise despite equal preference parameters.

While we cannot prove analytically that a non-degenerate distribution of Pareto weights exists for this economy, we can approximate the stationary distribution through simulation. Figure 4 plots the Pareto weight on agent $h$ in our economy in a simulation over 1 million quarters. Panel (a) of the figure shows the simulated path and panel (b) shows the distribution. The figure shows that during the simulation the Pareto weight remains far from the boundaries of 0 and 1. As with simulating any Markov chain to approximate a distribution, we only observe the states the chain enters during the simulation. That is, we can say that we have not detected any problems concerning survival, but we cannot prove that no such problems exist. However, this exercise suggests that the survival of the agents in the short simulations considered above is not a primary concern.

\section{Discussion}

Section 4.4 shows how the model with recursive as opposed to additive preferences, delivers the main result. In this section we discuss how the results are affected by varying key parameters. 


\subsection{Varying the elasticity of substitution and home bias}

The elasticity of substitution between intermediate goods $\sigma$ is often a key parameter in two-country business cycle models. That is also the case in this paper. This elasticity and the degree of home bias in final goods production jointly determine the steady state import ratio. Here we consider how varying these parameters affects our main result. Table 4 shows how the standard deviation of output and the relative standard deviation of the real exchange rate change as we change the elasticity of substitution. For each value of $\sigma$, there is a corresponding change in the home bias parameter $\eta$ so that the model continues to match the import ratio. Higher values of $\sigma$ then correspond with lower values of $\eta$.

It is clear from table 4 that a low elasticity of substitution and a high degree of home bias are required for the model to match the relative volatility of the real exchange rate in the data. Home bias is the only source of heterogeneity in this model, and the mechanism proposed in this paper relies on a heterogeneous response to productivity shocks across countries. When intermediate goods are substitutable, there is a smaller response in the relative price of intermediate goods to productivity shocks. When home bias is low, fluctuations in the terms of trade have smaller effects on the real exchange rate (see equation (27)).

The effects of these alternative parameterizations are also reflected in the Pareto weight dynamics in the planner's problem. High substitutability and low home bias means that the impact of technology shocks on the continuation utility of the two agents is similar. The shock therefore produces more similar responses in their marginal utilities of consumption which is reflected in muted responses in both real exchange rates and Pareto weights.

Table 4 also shows that a higher degree of substitutability increases the standard deviation of output. As final goods producing firms in both countries can increase production by substituting towards the more abundant good, the effect on relative prices is reduced and the response in production in the more productive country is larger. The model's ability to fit the relative volatility of the real exchange rate in the baseline case therefore comes at the cost of a reduced ability to fit the volatility of output. This is similar to Rabanal et al. (2011). As is apparent from both table 4 and the impulse responses in figure 1 however, this is not what drives our results.

Finally, table 4 shows that although a low elasticity of substitution and high home bias are needed to match the relative volatility in the data, the result that recursive preferences amplify real exchange rate movements holds more generally. For $\sigma=1.5$ for example the model with recursive preferences produces both a higher standard deviation in output and a higher relative volatility of the real exchange rate.

\subsection{Varying the productivity process}

The results presented in section 4.4 were produced under the baseline calibration with a cointegrated productivity process. As pointed out there, the permanent effects of technology 
Varying $\sigma$, import ratio fixed

\begin{tabular}{llllll}
\hline & \multicolumn{2}{l}{ Recursive preferences } & & \multicolumn{2}{l}{ Additive preferences } \\
\cline { 2 - 3 } \cline { 5 - 6 } & $\operatorname{sd}(y)$ & $\operatorname{rsd}(e)$ & & $\operatorname{sd}(y)$ & $\operatorname{rsd}(e)$ \\
\hline Data & 1.58 & 3.06 & 1.58 & 3.06 \\
\hline$\sigma=1.5$ & 0.99 & 0.82 & 0.95 & 0.59 \\
$\sigma=1.2$ & 0.93 & 1.13 & 0.91 & 0.71 \\
$\sigma=1.0$ & 0.89 & 1.47 & 0.90 & 0.83 \\
$\sigma=0.9$ & 0.85 & 1.71 & 0.89 & 0.89 \\
$\sigma=0.8$ & 0.81 & 2.02 & 0.87 & 0.98 \\
$\sigma=0.7$ & 0.79 & 2.37 & 0.86 & 1.05 \\
$\sigma=0.6$ & 0.74 & 2.96 & 0.85 & 1.16 \\
$\sigma=0.5$ & 0.71 & 3.65 & 0.80 & 1.26 \\
\hline
\end{tabular}

Table 4: Second moments from HP-filtered simulated series. Moments are averages over 100 simulations of 125 periods.

shocks generate a high volatility in the stochastic discount factor through the effects on the long-run components. In the previous international macroeconomics literature it has instead been common to specify productivity as a stationary vector autoregression. Here we investigate how our results are affected by an alternative specification of the productivity process.

The alternative specification we use we obtain from the estimated process in Heathcote and Perri (2002). ${ }^{18}$ They let the log of productivity follow a stationary VAR(1), and in their benchmark case this process is specified as:

$$
\left(\begin{array}{l}
\log z_{h, t+1} \\
\log z_{f, t+1}
\end{array}\right)=\left(\begin{array}{cc}
0.97 & 0.025 \\
0.025 & 0.97
\end{array}\right)\left(\begin{array}{l}
\log z_{h} \\
\log z_{f}
\end{array}\right)+\left(\begin{array}{c}
\varepsilon_{h, t+1} \\
\varepsilon_{f, t+1}
\end{array}\right)
$$

where $\left(\varepsilon_{h, t}, \varepsilon_{f, t}\right)^{\prime} \sim N(0, \Sigma)$, and the standard deviation of the productivity shocks is set to $\sigma_{\varepsilon}=0.0073$ and their correlation is set to 0.29 .

Table 5 shows how the results in table 2 change when the productivity process is stationary. In that case the model cannot match the high relative volatility of the real exchange rate even with recursive preferences. Equation (27) shows that a high real exchange rate volatility requires large responses in the terms of trade. With a stationary productivity process this response is smaller since the effects of a technology shock is not as persistent. To match the relative volatility of the real exchange rate in the data we therefore require productivity to be cointegrated across countries. In addition, when productivity is stationary, the model

\footnotetext{
${ }^{18}$ Note that Heathcote and Perri (2002) estimate a process for TFP, not the labor-augmenting TFP used in section (2.3.2). When solving the alternative model take this change in the production function into account.
} 
does not produce positive comovements in investment and employment, and the volatility of the stochastic discount factors is reduced.

Figure 7 in appendix B reproduces figure 1 and adds impulse responses for the case with a stationary productivity process and recursive preferences. The figure shows that the fall in the Pareto weight and corresponding real exchange rate response is considerably smaller when the shocks are stationary. There is a response in the Pareto weight however, that reflects the heterogeneous effect of productivity shocks on agents' future utilities. Hence, the result that the real exchange rate movements are amplified in the model with recursive preferences continues to hold.

\section{Conclusion}

This paper argues that a model with recursive preferences can jointly generate variability in real exchange rates and volatile stochastic discount factors. When preferences are non-separable over time and across states in the future, shocks that impact future growth prospects may influence the current marginal utility of consumption. Shocks that have different long-term implications across countries will then impact the relative value of consumption today which is reflected in the real exchange rate. Agents' preferences are therefore crucial for generating real exchange rate movements that are not simply the result of current differences in consumption and leisure. In addition, key elements are productivity shocks with a unit root which imply that current shocks have large effects on future allocations, and home bias which implies that these shocks affect countries differently.

Some standard puzzles in international economics remain. In the optimal risk sharing arrangement consumption is more correlated across countries in the model than in the data, and it is more correlated across countries than output is. In addition, the larger movements in the real exchange rate in the model with recursive preferences, still correspond with relatively larger increases in consumption in the country hit with the positive shock to productivity. In the benchmark calibration the model can therefore not account for the disconnect between real exchange rates and relative consumptions identified by Backus and Smith (1993).

An interesting avenue for future research is to consider whether alternative sources of business cycle fluctuations can help resolve the remaining anomalies in the current framework. For example Raffo (2009) argues that investment specific technology shocks can break the perfect correlation between relative consumptions and the real exchange rate. However, Mandelman et al. (2011) argue that this only holds when these shocks are calibrated with a higher volatility than the data implies. In a model where agents have recursive preferences and are concerned with smoothing future utility, these shocks may have more of an impact. 
Results — additive and recursive preferences, stationary productivity process

\begin{tabular}{lllllll}
\hline & $\operatorname{sd}(y)$ & $\operatorname{rsd}(c)$ & $\operatorname{rsd}(\iota)$ & $\operatorname{rsd}(n)$ & $\operatorname{rsd}(e)$ & $\rho(e)$ \\
\hline Data & 1.58 & 0.76 & 4.55 & 0.75 & 3.06 & 0.82 \\
\hline Additive & 1.10 & 0.57 & 2.74 & 0.32 & 0.60 & 0.76 \\
Recursive & 1.07 & 0.57 & 2.67 & 0.32 & 1.00 & 0.73
\end{tabular}

\begin{tabular}{llllll} 
& \multicolumn{2}{l}{ Correlations } & \\
\cline { 2 - 5 } & $(y, n)$ & $(y, c)$ & $(y, \iota)$ & $(y, n x)$ & $\left(e, c_{h} / c_{f}\right)$ \\
\hline Data & 0.87 & 0.84 & 0.91 & -0.49 & -0.04 \\
\hline Additive & 0.96 & 0.98 & 0.96 & -0.58 & 0.99 \\
Recursive & 0.95 & 0.97 & 0.96 & -0.58 & 1.00
\end{tabular}

\begin{tabular}{lllll} 
& \multicolumn{4}{l}{ Correlations } \\
\cline { 2 - 5 } & $\left(y_{h}, y_{f}\right)$ & $\left(c_{h}, c_{f}\right)$ & $\left(\iota_{h}, \iota_{f}\right)$ & $\left(n_{h}, n_{f}\right)$ \\
\hline Data & 0.44 & 0.36 & 0.28 & 0.40 \\
\hline Additive & 0.32 & 0.56 & -0.20 & -0.05 \\
Recursive & 0.40 & 0.70 & -0.15 & -0.08 \\
\hline
\end{tabular}

Table 5: Second moments from HP-filtered simulated series for the model when productivity follows a stationary $\operatorname{VAR}(1)$ process. The other parameters of the model take on the same values as in table 1 . Notation and procedure are the same as for table 2 . 


\section{A Normalized system of equations}

Since $\log Z_{h, t}$ and $\log Z_{f, t}$ are both integrated of order 1, we normalize our system of equations to obtain a stationary system in terms of rescaled variables. The rescaled variables, for $i, j \in\{h, f\}$, are:

$$
\begin{aligned}
& V_{i, t}=\frac{U_{i, t}}{\left(Z_{i, t}\right)^{\tau}} \quad c_{i, t}=\frac{C_{i, t}}{Z_{i, t}} \quad \iota_{i, t}=\frac{I_{i, t}}{Z_{i, t}} \quad k_{i, t}=\frac{K_{i, t}}{Z_{i, t-1}} \\
& x_{i j, t}=\frac{X_{i j, t}}{Z_{i, t}} \quad y_{i, t}=\frac{Y_{i, t}}{Z_{i, t}} \quad w_{i, t}=\frac{W_{i, t}}{Z_{i, t}} \quad a_{i, t}=\frac{A_{i, t}}{Z_{i, t}} \\
& g_{i, t+1}=\frac{Z_{i, t+1}}{Z_{i, t}} \quad \tilde{z}_{t}=\frac{Z_{f, t}}{Z_{h, t}}
\end{aligned}
$$

The vector of state variables for the normalized system is

$$
s_{t}=\left\{k_{h, t}, k_{f, t}, \bar{V}_{f, t}, \tilde{z}_{t}, g_{h, t}, g_{f, t}\right\}
$$

The planner's value function is written $V_{h}\left(s_{t}\right)$, and the planner chooses

$$
\left\{c_{i, t}, n_{i, t}, x_{i j, t}, \iota_{i, t}, k_{i, t+1},\left\{\bar{V}_{f, t+1}\right\}\right\}
$$

for $i, j \in\{h, f\}$ to maximize $V_{h}\left(s_{t}\right)$.

\section{A.1 Equations to solve for equilibrium}

Cross-country consumption allocations:

$$
\lambda_{t}^{*} \tilde{z}_{t}^{\tau \rho-1}\left(\frac{c_{f, t}}{c_{h, t}}\right)^{\tau \rho-1}\left(\frac{1-n_{f, t}}{1-n_{h, t}}\right)^{(1-\tau) \rho}=e_{t}
$$

Intermediate goods allocations:

$$
\begin{aligned}
e_{t} & =\frac{\eta}{1-\eta}\left(\frac{x_{f h, t}}{x_{h h, t}}\right)^{\frac{1}{\sigma}}\left(\frac{G_{h}}{G_{f}}\right)^{\frac{1}{\sigma}} \\
e_{t} & =\frac{1-\eta}{\eta}\left(\frac{x_{f f, t}}{x_{h f, t}}\right)^{\frac{1}{\sigma}}\left(\frac{G_{h}}{G_{f}}\right)^{\frac{1}{\sigma}} \\
\left(\frac{k_{h, t}}{g_{h, t}}\right)^{\theta} n_{h, t}^{1-\theta} & =x_{h h, t}+x_{f h, t} \tilde{z}_{t} \\
\left(\frac{k_{f, t}}{g_{f, t}}\right)^{\theta} n_{f, t}^{1-\theta} & =\frac{x_{h f, t}}{\tilde{z}_{t}}+x_{f f, t}
\end{aligned}
$$


Final goods allocations: $i \in\{h, f\}$

$$
G_{i}\left(x_{i h, t}, x_{i f, t}\right)=c_{i, t}+\iota_{i, t}
$$

Labor allocations: $i \in\{h, f\}$

$$
\frac{n_{i, t}}{1-n_{i, t}}=\eta\left(\frac{G_{i, t}}{x_{i i, t}}\right)^{\frac{1}{\sigma}} \frac{\tau}{1-\tau}(1-\theta)\left(\frac{k_{i, t}}{n_{i, t}}\right)^{\theta} \frac{1}{g_{i, t}^{\theta}} \frac{n_{i, t}}{c_{i, t}}
$$

Stochastic discount factors: $i \in\{h, f\}$

$$
m_{i, t+1}=\beta g_{i, t+1}^{\tau \rho-1}\left(\frac{c_{i, t+1}}{c_{i, t}}\right)^{\tau \rho-1}\left(\frac{1-n_{i, t+1}}{1-n_{i, t}}\right)^{(1-\tau) \rho}\left(\frac{g_{i, t+1}^{\tau} V_{i, t+1}}{\zeta_{t}\left(g_{i, t+1}^{\tau} V_{i, t+1}\right)}\right)^{\alpha-\rho}
$$

Rental rate of capital: $i \in\{h, f\}$

$$
r_{i, t+1}=\eta\left(\frac{G_{i, t+1}}{x_{i i, t+1}}\right)^{\frac{1}{\sigma}} \theta\left(\frac{g_{i, t+1} n_{i, t+1}}{k_{i, t+1}}\right)^{1-\theta}
$$

Pricing:

$$
1=\mathbb{E}_{t} m_{i, t+1}\left(r_{i, t+1}+1-\delta\right)
$$

Capital evolution:

$$
\begin{aligned}
& k_{h, t+1}=(1-\delta) \frac{k_{h, t}}{g_{h, t}}+\iota_{h, t} \\
& k_{f, t+1}=(1-\delta) \frac{k_{f, t}}{g_{f, t}}+\iota_{f, t}
\end{aligned}
$$

Pareto weight evolution:

$$
\frac{\lambda_{t+1}^{*}\left(s_{t+1}\right)}{\lambda_{t}^{*}\left(s_{t}\right)}=\left(\frac{g_{h, t+1}^{\tau} V_{h, t+1}\left(s_{t+1}\right)}{\zeta_{t}\left(g_{h, t+1}^{\tau} V_{h, t+1}\right)}\right)^{\rho-\alpha}\left(\frac{g_{f, t+1}^{\tau} \bar{V}_{f, t+1}}{\zeta_{t}\left(g_{f, t+1}^{\tau} \bar{V}_{f, t+1}\right)}\right)^{\alpha-\rho}
$$

This gives one equation for each possible realization of the state next period.

\section{Exogenous variables ${ }^{19}$}

$$
\begin{aligned}
\log g_{h, t+1} & =\phi_{0 h}-\phi_{1 h} \log \tilde{z}_{t}+\varepsilon_{h, t+1} \\
\log g_{f, t+1} & =\phi_{0 f}-\phi_{1 f} \log \tilde{z}_{t}+\varepsilon_{f, t+1} \\
\log \tilde{z}_{t+1} & =\log \tilde{z}_{t}+\log g_{h, t+1}-\log g_{f, t+1}
\end{aligned}
$$

\footnotetext{
${ }^{19}$ The laws of motion for the productivity state variables after imposing that the cointegrating vector is $(1,-1)$ and no constant term in the cointegrating relationship.
} 


\section{B Additional impulse response functions}

Figure 5 plots impulse responses in wages and the rental rate of capital. Figure 6 plots impulse responses in the prices of intermediate goods in each country in terms of the final good produced in that country. Figure 7 plots the same impulse responses as in figure 1 and adds plots for the case where agents have recursive preferences, but productivity is specified by the stationary process estimated by Heathcote and Perri (2002).
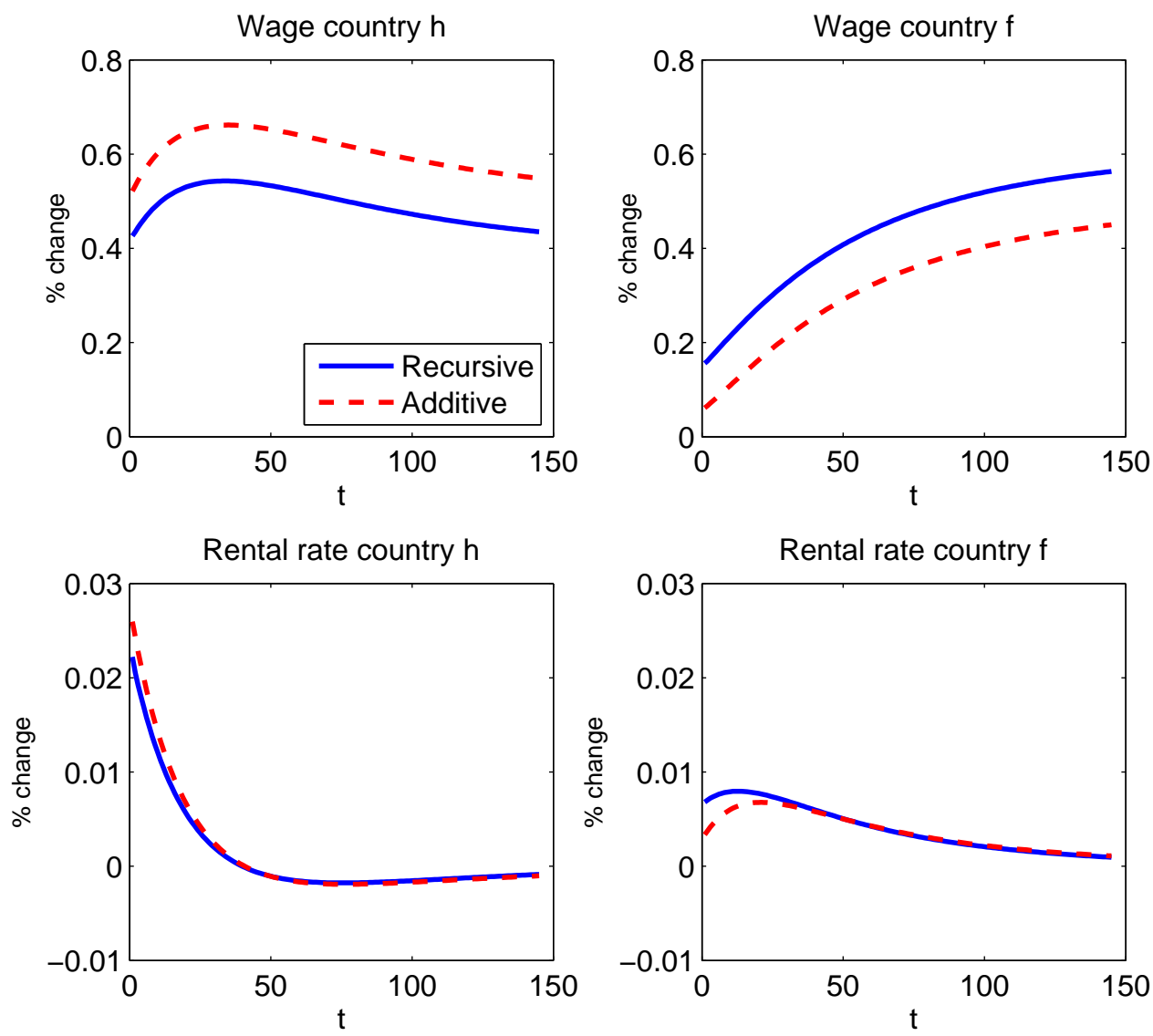

Figure 5: Impulse response functions after a one standard deviation shock to productivity in country $h$. The impulse responses are plotted as percentage difference from the balanced growth path for the model with additive preferences $(1-\alpha=2)$ and with recursive preferences $(1-\alpha=100)$. Note that the wage and the rental rate in each country are in units of the final good produced domestically. 

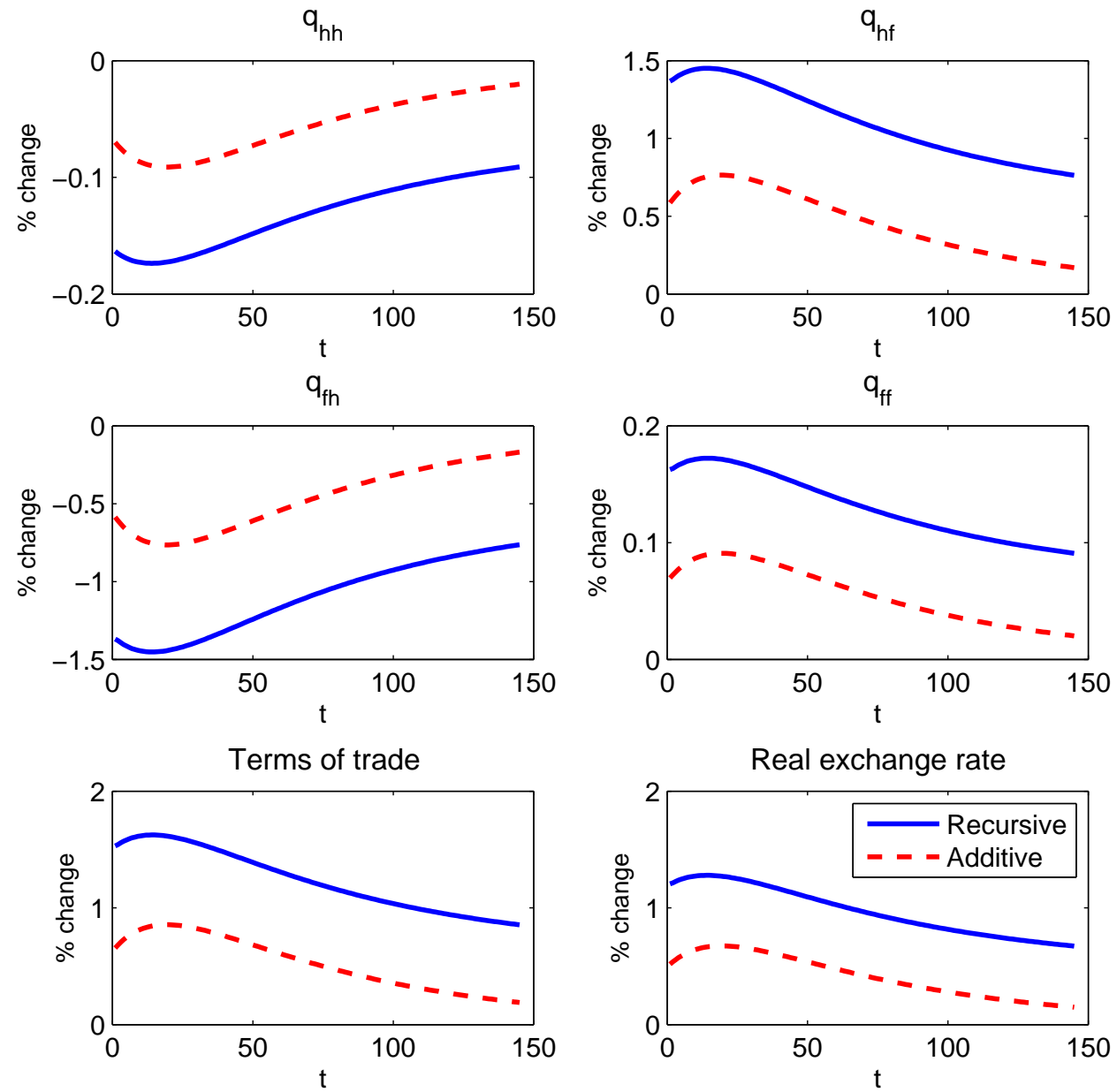

Figure 6: Impulse response functions after a one standard deviation shock to productivity in country $h$. The impulse responses are plotted as percentage difference from the balanced growth path for the model with additive preferences $(1-\alpha=2)$ and with recursive preferences $(1-\alpha=100)$. Note that $q_{i j}$ denotes the price of intermediate good $j$ in country $i$ in units of the final good produced in country $i$. 

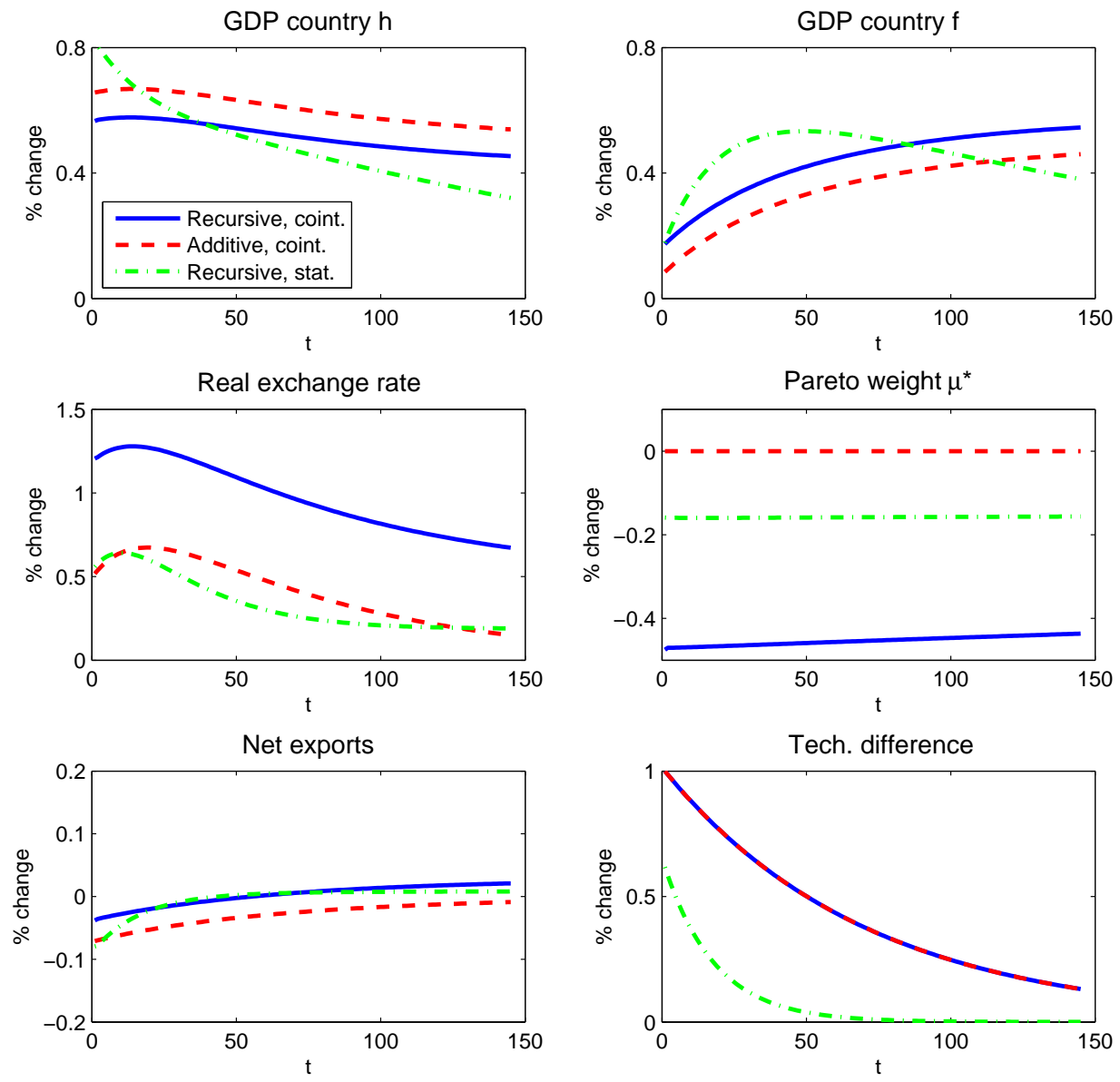

Figure 7: Impulse response functions after a one standard deviation shock to productivity in country $h$. The impulse responses are plotted as percentage difference from the balanced growth path for the model with additive preferences $(1-\alpha=2)$ and with recursive preferences $(1-\alpha=100)$. 'coint' denotes the case where productivity is cointegrated; 'stat' denotes the case where productivity is stationary. 


\section{References}

Evan W. Anderson. The dynamics of risk-sensitive allocations. Journal of Economic Theory, 125(2):93-150, 2005.

Martin M. Andreasen. How non-gaussian shocks affect risk premia in non-linear DSGE models. Bank of England Working paper No. 417, March 2011.

David K. Backus and Gregor W. Smith. Consumption and real exchange rates in dynamic economies with non-traded goods. Journal of International Economics, 35(3-4):297-316, 1993.

David K. Backus, Patrick J. Kehoe, and Finn E. Kydland. International real business cycles. Journal of Political Economy, 100(4):745-775, 1992.

David K. Backus, Patrick J. Kehoe, and Finn E. Kydland. Dynamics of the trade balance and the terms of trade: The J-curve? American Economic Review, 84(1):84-103, 1994.

David K. Backus, Silverio Foresi, and Chris I. Telmer. Affine term structure models and the forward premium anomaly. Journal of Finance, 56(1):279-304, 2001.

Ravi Bansal and Amir Yaron. Risks for the long run: A potential resolution of asset pricing puzzles. Journal of Finance, 59(4):1481-1509, 2004.

Fransisco Barillas, Lars Peter Hansen, and Thomas J. Sargent. Doubts or variability? Journal of Economic Theory, 144(6):2388-2418, 2008.

Pierpaolo Benigno and Salvatore Nisticò. International portfolio allocation under model uncertainty. American Economic Journal: Macroeconomics, 4(1):144-189, 2012.

Rhys Bidder and Matthew E. Smith. Robust animal spirits. Journal of Monetary Economics, 2012. In press.

Martin Bodenstein. Trade elasticity of substitution and equilibrium dynamics. Journal of Economic Theory, 145(3):1033-1059, 2010.

Varadarajan V. Chari, Patrick J. Kehoe, and Ellen R. McGrattan. Can sticky price models generate volatile and persistent real exchange rates? Review of Economic Studies, 69(3): 533-563, 2002.

Riccardo Colacito and Mariano M. Croce. Risks for the long-run and the real exchange rate. Journal of Political Economy, 119(1):153-181, 2011a.

Riccardo Colacito and Mariano M. Croce. International asset pricing with risk-sensitive agents. Working Paper, June 2011b.

Riccardo Colacito and Mariano M. Croce. Recursive allocations and wealth distribution with multiple goods: Existence, survivorship, and dynamics. Working Paper, August 2011c. 
Giancarlo Corsetti, Luca Dedola, and Sylvain Leduc. International risk sharing and the transmission of productivity shocks. Review of Economic Studies, 75(2):443-473, 2008.

Larry G. Epstein and Stanley E. Zin. Substitution, risk aversion, and the temporal behavior of consumption and asset returns: A theoretical framework. Econometrica, 57(4):937-969, 1989.

Jonathan Heathcote and Fabrizio Perri. Financial autarky and international business cycles. Journal of Monetary Economics, 49(3):601-627, 2002.

Robert E. Lucas Jr. and Nancy L. Stokey. Optimal growth with many consumers. Journal of Economic Theory, 32(1):139-171, 1984.

Georg Kaltenbrunner and Lars Lochstoer. Long-run risk through consumption smoothing. Review of Financial Studies, 23(8):3190-3224, 2010.

Rui Kan. Structure of pareto optima when agents have stochastic recursive preferences. Journal of Economic Theory, 66(2):626-631, 1995.

Robert G. King, Charles I. Plosser, and Sergio T. Rebelo. Production growth and business cycles. Journal of Monetary Economics, 21(2-3):195-232, 1988.

David M. Kreps and Evan L. Porteus. Temporal resolution of uncertainty and dynamic choice theory. Econometrica, 46(1):185-200, 1978.

Federico S. Mandelman, Pau Rabanal, Juan F. Rubio-Ramirez, and Diego Vilan. Investment-specific technology shocks and international business cycles: An empirical assessment. Review of Economic Dynamics, 14(1):136-155, 2011.

Pau Rabanal, Juan F. Rubio-Ramirez, and Vicente Tuesta. Cointegrated TFP processes and international business cycles. Journal of Monetary Economics, 58(2):156-171, 2011.

Andrea Raffo. Net exports, consumption volatility and international business cycle models. Journal of International Economics, 75(1):14-29, 2008.

Andrea Raffo. Technology shocks: Novel implications for international business cycles. Mimeo. Board of Governors of the Federal Reserve System, 2009.

Glenn D. Rudebusch and Eric T. Swanson. The bond premium in a DSGE model with long-run real and nominal risks. Federal Reserve Bank of San Fransisco Working paper, 2011.

Eric T. Swanson. Risk aversion, the labor margin, and asset pricing in DSGE models. Federal Reserve Bank of San Fransisco Working paper, 2009.

Thomas D. Tallarini. Risk-sensitive real business cycles. Journal of Monetary Economics, 45(3):507-532, 2000. 
Jules H. van Binsbergen, Jesus Fernandez-Villaverde, Ralph S. J. Koijen, and Juan F. Rubio-Ramirez. Working with epstein-zin preferences: Computation and likelihood estimation of DSGE models with recursive preferences. Working Paper, 2008.

Jules H. van Binsbergen, Jesus Fernandez-Villaverde, Ralph S. J. Koijen, and Juan F. Rubio-Ramirez. The term-structure of interest rates in a DSGE model with recursive preferences. Working Paper, 2010.

Philippe Weil. Nonexpected utility in macroeconomics. The Quarterly Journal of Economics, 105(1):29-42, 1990. 